\title{
Evaluation and Comparison of Noah and Pleim-Xiu Land Surface Models in MM5 Using GÖTE2001 Data: Spatial and Temporal Variations in Near-Surface Air Temperature
}

\author{
J.-F. Miao, D. Chen, And K. Borne \\ Department of Earth Sciences, Göteborg University, Göteborg, Sweden
}

(Manuscript received 14 September 2006, in final form 6 March 2007)

\begin{abstract}
In this study, the performance of two advanced land surface models (LSMs; Noah LSM and Pleim-Xiu LSM) coupled with the fifth-generation Pennsylvania State University-National Center for Atmospheric Research Mesoscale Model (MM5), version 3.7.2, in simulating the near-surface air temperature in the greater Göteborg area in Sweden is evaluated and compared using the GÖTE2001 field campaign data. Further, the effects of different planetary boundary layer schemes [Eta and Medium-Range Forecast (MRF) PBLs] for Noah LSM and soil moisture initialization approaches for Pleim-Xiu LSM are investigated. The investigation focuses on the evaluation and comparison of diurnal cycle intensity and maximum and minimum temperatures, as well as the urban heat island during the daytime and nighttime under the clear-sky and cloudy/rainy weather conditions for different experimental schemes. The results indicate that 1) there is an evident difference between Noah LSM and Pleim-Xiu LSM in simulating the near-surface air temperature, especially in the modeled urban heat island; 2) there is no evident difference in the model performance between the Eta PBL and MRF PBL coupled with the Noah LSM; and 3) soil moisture initialization is of crucial importance for model performance in the Pleim-Xiu LSM. In addition, owing to the recent release of MM5, version 3.7.3, some experiments done with version 3.7.2 were repeated to reveal the effects of the modifications in the Noah LSM and Pleim-Xiu LSM. The modification to longwave radiation parameterizations in Noah LSM significantly improves model performance while the adjustment of emissivity, one of the vegetation properties, affects Pleim-Xiu LSM performance to a larger extent. The study suggests that improvements both in Noah LSM physics and in Pleim-Xiu LSM initialization of soil moisture and parameterization of vegetation properties are important.
\end{abstract}

\section{Introduction}

The fifth-generation Pennsylvania State UniversityNational Center for Atmospheric Research Mesoscale Model (MM5; Dudhia 1993; Grell et al. 1995) has been widely used in operational numerical weather forecasting, air quality studies (e.g., Grell et al. 2000; Seaman 2000; Olerud and Sims 2003; Kemball-Cook et al. 2004; Tonnesen et al. 2005; Miao 2006; Miao et al. 2006), and wind energy studies (Landberg et al. 2003). The extensive literature shows that the land surface processes play an important role not only in large-scale atmospheric models (e.g., Chen and Avissar 1994a; Polcher

Corresponding author address: Dr. Junfeng Miao, Department of Earth Sciences, Göteborg University, P.O. Box 460, 40530 Göteborg, Sweden.

E-mail: junfeng@gvc.gu.se et al. 1998; Desborough 1999; Chen 2005) but also in regional and mesoscale atmospheric processes including precipitation (e.g., Avissar and Pielke 1989; Chen and Avissar 1994b; Tilley and Lynch 1998; Chen and Dudhia 2001a,b; Chen et al. 2001; Xiu and Pleim 2001; Ek et al. 2003; Trier et al. 2004; Mölders and Walsh 2004). During the development of MM5, two advanced land surface models [LSMs; Pleim-Xiu LSM (Xiu and Pleim 2001) and Noah LSM (Chen and Dudhia 2001a)] were coupled into the MM5 modeling system to represent surface-atmosphere interactions. These model components are under continuous development, and their enhancement and improvement enable the MM5 to be applied more widely and with more confidence.

For model development and applications, the evaluation of model performance against observational data and intercomparison of different schemes within the same model are important, as they can suggest modifi-

DOI: 10.1175/JAM2561.1

(C) 2007 American Meteorological Society 
cations and/or refinements to physical parameterizations. To date, only a few studies from the developers have validated the performances of Noah LSM and Pleim-Xiu LSM in MM5 (Chen and Dudhia 2001a,b; Xiu and Pleim 2001) and compared the performance of their respective LSM with the slab model ("standard" LSM in MM5), although the Noah LSM or likeness is increasingly validated and evaluated in climate mode (e.g., Sridhar et al. 2002; Hogue et al. 2005). To our knowledge, so far only a few comparative studies between these two LSMs have been undertaken (e.g., Olerud and Sims 2003; Kemball-Cook et al. 2004; Tonnesen et al. 2005). These studies show that the MM5-modeled results are sensitive to the choice of the LSMs. For the purposes of the Western Regional Air Partnership (WRAP), it may be helpful to explore the model's sensitivity to the LSMs (Kemball-Cook et al. 2004). The study results from the Project for Intercomparison of Land Surface Parameterization Schemes (PILPS) show that even similarly designed LSMs may provide appreciable differences in the results (e.g., Henderson-Sellers et al. 1995, 1996; Pitman et al. 1999). More studies are therefore needed to evaluate the performance of the LSMs and to compare their differences for certain applications. It is commonly known that evaluating model performance is very difficult because of the lack of high-resolution spatial and temporal observations to be compared with the model output (Sridhar et al. 2002). However, the GÖTE2001 campaign (Borne et al. 2005) provides us with a unique opportunity to evaluate the model with high resolutions. During the campaign spanning 2 weeks, nearsurface air temperature measurements at high spatial and temporal resolutions over a $25 \times 30 \mathrm{~km}^{2}$ area are available.

The purpose of this paper is to use the GÖTE2001 dataset to evaluate the performance of the LSMs with high spatial resolution, focusing on the temporal variation and spatial distribution of near-surface air temperature under different weather conditions. The main objectives of the study are threefold. The first is to evaluate the overall performance of the two LSMs at local scale over the greater Göteborg area along the Swedish west coast. The second is to examine the effect of different planetary boundary layer (PBL) schemes coupled with Noah LSM on the simulated surface air temperature. The third is to evaluate the impact of soil moisture initialization for Pleim-Xiu LSM on the estimated surface air temperature. Moreover, some sensitivity experiments are conducted to understand the effects of screen height and land surface characteristics on model performance.

\section{Model description and numerical experiments}

Version 3.7.2 of MM5, coupled with the Noah LSM (Chen and Dudhia 2001a) and the Pleim-Xiu LSM (Xiu and Pleim 2001), is used in this study. It was released on 12 May 2005 (available online at http://www. mmm.ucar.edu/mm5/mm5v3/v3mm5-chg-v3-7.html) and has some improvement and enhancement relative to previous versions, especially in the Noah LSM.

\section{a. Land surface models}

\section{1) NOAH LSM}

The Noah LSM used in MM5 (Chen and Dudhia 2001a,b) is based on coupling of the diurnally dependent Penman potential evaporation approach of Mahrt and Ek (1984), the multilayer soil model of Mahrt and Pan (1984), and the primitive canopy model of Pan and Mahrt (1987). It has been extended by Chen et al. (1996) to include the modestly complex canopy resistance approach of Jacquemin and Noilhan (1990) and by Koren et al. (1999) to include frozen ground physics. The LSM is used to predict soil moisture and temperature in 4 layers with thicknesses from top to bottom of $10,30,60$, and $100 \mathrm{~cm}$, as well as canopy moisture and water-equivalent snow depth. The LSM has one canopy layer, and its total depth of soil layers is $2 \mathrm{~m}$. The upper $1 \mathrm{~m}$ of soil serves as the root zone depth, and the lower $1 \mathrm{~m}$ of soil acts as a reservoir with gravity drainage. The LSM uses soil and vegetation types in handling evapotranspiration. The dominant vegetation type in each grid is selected to represent the grid vegetation characteristics when the model horizontal grid resolution is larger than $1 \mathrm{~km} \times 1 \mathrm{~km}$, and vegetation parameters (e.g., roughness length and albedo) depend on vegetation type [or, land use category (LUC)]. Soil thermal properties depend on soil type. More details on this LSM can be found in the related references (e.g., Chen and Dudhia 2001a,b; Sridhar et al. 2003; Ek et al. 2003). It is coupled with MM5 through the Eta PBL (Janjić 1990, 1994) and Medium-Range Forecast (MRF) PBL (Hong and Pan 1996) schemes, respectively. The coupled MM5-Noah model can diagnostically output 2-m air temperature above ground level (AGL).

\section{2) Pleim-XIU (PX) LSM}

The Pleim-Xiu LSM (Xiu and Pleim 2001; Pleim and Xiu 2003) is based on a set of five partial differential equations for soil temperature and soil moisture in two layers (1-cm surface layer and 1-m root zone layer) and canopy moisture (Pleim and Xiu 1995). Its key elements are a surface model dealing with soil moisture and evapotranspiration based on the Interactions be- 
tween Soil, Biosphere, and Atmosphere (ISBA) model (Noilhan and Planton 1989), and a nonlocal closure PBL model developed by Pleim and Chang (1992). Evaporation has three pathways: direct soil surface evaporation, vegetative evapotranspiration, and evaporation from wet canopies. Ground surface temperature is computed from the surface energy balance using a force-restore algorithm for heat exchange within the soil. In this LSM, a canopy shelter factor is used to account for shading within denser canopies. Soil moisture coefficients used in the prognostic soil moisture equations are formulated in terms of basic soil parameters such as field capacity, wilting point, saturation, and other thermal and hydraulic properties of the soil as described in the work of Jacquemin and Noilhan (1990). All soil properties are specified according to soil types. Vegetation parameters such as leaf area index (LAI), vegetation coverage, roughness length, and minimum stomatal resistance used in this LSM are aggregated to the grid cell using the 1-km data for these parameters and the weighted techniques (Xiu and Pleim 2001) when the model horizontal spacing is larger than $1 \mathrm{~km} \times 1 \mathrm{~km}$. Note that this LSM is only coupled with the PBL scheme developed by Pleim and Chang (1992) in the MM5. The coupled MM5-PX model can output 1.5-m (AGL) air temperature.

More details on the parameterization equations of the above LSMs can be found in Chen and Dudhia (2001a), Pleim and Xiu (1995), and Xiu and Pleim (2001).

\section{b. Atmospheric model configuration and physics}

The MM5 is set up with four nested domains (D1, D2, D3, and D4) with horizontal grid spacings of 54, 18, 6 , and $2 \mathrm{~km}$ (Fig. 1a). These four domains consist of 50 $\times 50,64 \times 55,62 \times 52$, and $40 \times 46$ horizontal grids (N-S direction by E-W direction), respectively. D1 has the size of $2700 \mathrm{~km} \times 2700 \mathrm{~km}$ covering Scandinavia and is used to simulate the large-scale meteorological conditions. The inner three domains with finer resolutions are used to capture mesoscale and local-scale features, of which the innermost domain (D4) is the area of interest (Fig. 1b). All domains have 34 layers in the vertical direction. The lowest layer is at approximately $19 \mathrm{~m}$ AGL. The model top is at $100 \mathrm{hPa}$ with a radiative boundary condition for all domains. The physics used with the model for all domains is given in Table 1. A two-way nesting scheme is used, and data assimilation is not used in the model.

\section{c. Model initialization and numerical experiment}

The European Centre for Medium-Range Weather

Forecasts (ECMWF) operational analysis pressure

(a)

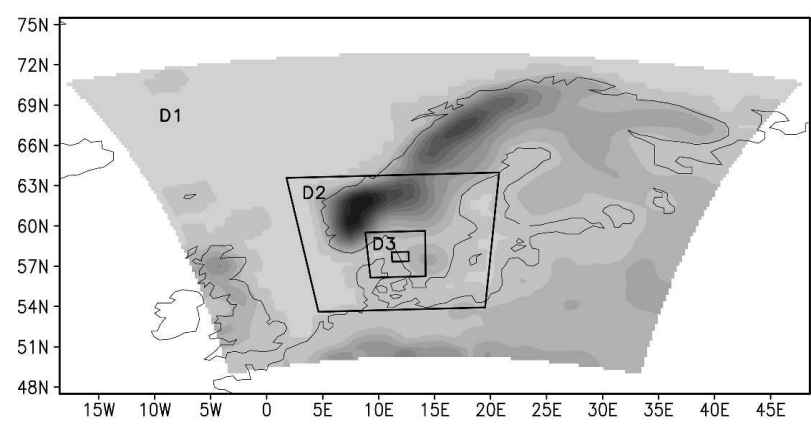

$0 \quad 100 \quad 200 \quad 300 \quad 400 \quad 500 \quad 600 \quad 700 \quad 800 \quad 900 \quad 10001100$

\section{(b)}

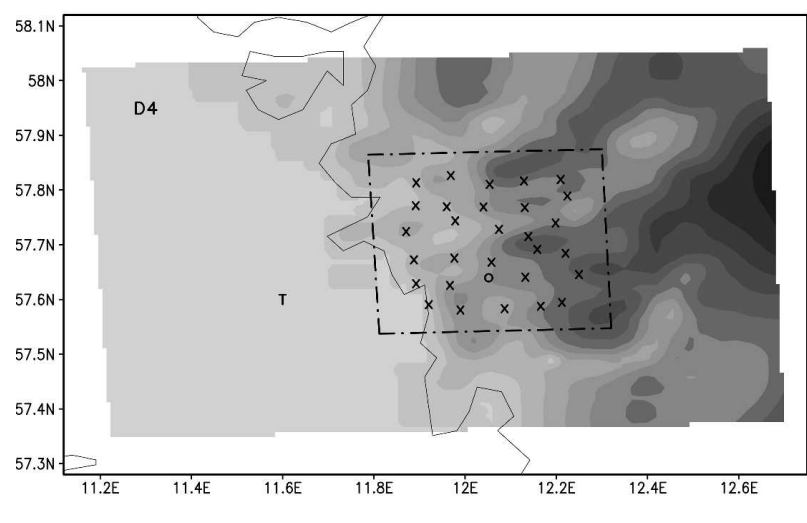

$\begin{array}{lllllllllll}0 & 20 & 40 & 60 & 80 & 100 & 120 & 140 & 160 & 180 & 200\end{array}$

FIG. 1. (a) Modeling domains and grid configuration. Domains $1,2,3$, and 4 (denoted by D1, D2, D3, and D40) have a horizontal grid spacing of $54,18,6$, and $2 \mathrm{~km}$, respectively. The innermost domain refers to D4. Shaded is the model terrain (m) with $54-\mathrm{km}$ grid spacing for D1. (b) Magnified view of D4 and model terrain (m) with $2-\mathrm{km}$ grid spacing, as well as the layout of Tinytalk/ Tinytag observational sites ( 30 sites), marked with cross (29 sites) and open circle ( 1 site). The data at the site with open circle are missing. The $\mathrm{T}$ (Trubaduren) is a lighthouse station, which is used to correct the interpolation of surface air temperature near the coastline from observation sites to model grids. The rectangle marked by the dash-dot line is referred to as Tinytalk area, over which surface air temperature ( $2 \mathrm{~m}$ AGL) was measured using Tinytalk/Tinytag instruments at about $5-\mathrm{km}$-spaced sites.

level data with the spatial resolution of $0.5^{\circ}$ by $0.5^{\circ}$ and the temporal resolution of $6 \mathrm{~h}$ are used in this study for initial and lateral boundary conditions. The 25-category U.S. Geological Survey vegetation data and global 17category soil data are used. As an example of vegetation information, Fig. 2 shows the dominant land use category distribution in D4 at 2-km grid spacing. There are four dominant LUCs within this domain: urban, crop, forest, and water, and significant sea-land contrast and urban-rural differences exist.

In this study, we evaluate and compare the simula- 
TABLE 1. Physical parameterization schemes used in MM5.

\begin{tabular}{|c|c|}
\hline Physics option & Parameterization scheme \\
\hline Cumulus parameterization & Kain-Fritsch including shallow convection (KF2; Kain 2004) \\
\hline PBL & $\begin{array}{l}\text { Eta PBL scheme (Janjić 1990, 1994), MRF model scheme (Hong and Pan 1996), } \\
\text { Pleim-Chang PBL scheme (Pleim and Chang 1992) }\end{array}$ \\
\hline Explicit moisture (microphysics) & Simple ice microphysics scheme (Dudhia 1989) \\
\hline Radiation & $\begin{array}{l}\text { Cloud radiation shortwave scheme (Dudhia 1989), Rapid Radiative Transfer Model (RRTM) } \\
\text { longwave scheme (Mlawer et al. 1997) }\end{array}$ \\
\hline $\begin{array}{l}\text { Surface parameterization } \\
\quad \text { (land surface process) }\end{array}$ & Noah LSM (Chen and Dudhia 2001a), Pleim-Xiu LSM (Xiu and Pleim 2001) \\
\hline
\end{tabular}

tions of near-surface air temperature using two advanced LSMs. Considering the availability of the coupling of these two LSMs to PBL schemes in MM5, as well as the method of soil moisture initialization, four numerical experiments (Table 2) are designed and carried out. Since the LSMs are associated with certain PBL schemes, the difference between various experiments are not only due to different LSMs but also the associated PBL schemes. Soil moisture for the first 3 experiments is initialized using ECMWF soil moisture data (4 layers: 0-7, 7-28, 28-100, and 100-289 cm), while that for the last experiment is initialized using climatological values based on land use category and season. Note that there are some differences in using and handling soil and vegetation parameters between the two LSMs. Also, all parameters for LSMs are kept as they are (default). For clarity, some parameters related to vegetation and/or soil used in Noah LSM and Pleim-Xiu LSM for LUCs in D4 are highlighted in Tables 3 and 4, respectively.

All simulations are conducted from 0000 UTC 6 May to 0000 UTC 21 May 2001 with model output at hourly intervals. The first day is discarded as spinup and the remaining 14 days are used for the analyses.

\section{GÖTE2001 data and evaluation methods}

The observational data used for evaluation in this study are from 2-m air temperature measurement AGL using Tinytalk/Tinytag dataloggers during the GÖTE2001 campaign (Borne et al. 2005), which was made at 30 sites over a $25 \times 30 \mathrm{~km}^{2}$ area in a coastal environment with complex land use (Figs. $1 \mathrm{~b}$ and 2). Over these sites only 2-m air temperature was measured and recorded. Each site represents one $5 \mathrm{~km} \times 5 \mathrm{~km}$ area with typical land use characteristics within the cell. The data for 29 of 30 sites are available during the period of 7-20 May 2001, while the data for one site are missing. Data were measured and stored every $16 \mathrm{~min}$. The database is called the GÖTE2001 data in this study. During the GÖTE2001 campaign, the Swedish west coast was dominated by a high pressure system from 7 to 13 May 2001 (W1, first week) and by a low pressure system from 14 to 21 May 2001 (W2, second week).

In this study, the observed surface air temperature is linearly interpolated temporally from $16-\mathrm{min}$ to 1 -h time intervals to match the time interval of model output. The modeled near-surface $(2 \mathrm{~m} / 1.5 \mathrm{~m})$ air temperature in D4 is horizontally interpolated onto the observational sites using bilinear interpolation. The interpolated model results are used to compare with the observed results for time series evaluation.

To examine the similarity of the pattern between modeled and observed results, air temperature at $2 \mathrm{~m}$ AGL at the observational sites is interpolated onto the model grids over the subdomain in D4 (Figs. 1b and 2) using the Griddata method (Sandwell 1987) and bilinear method.

Also, several statistical measures over space and/or time (e.g., Hogrefe et al. 2001; Zhong and Fast 2003; Zhong et al. 2005; Miao et al. 2007) are computed to quantitatively evaluate the LSM performance. These five measures are 1) the mean bias error,

$$
\operatorname{MBE}=\frac{1}{N} \sum_{i=1}^{N} \phi_{i}^{\prime},
$$

which represents systematic errors caused by the consistent misrepresentation of local properties (e.g., land use and topography) and the physical mechanisms (e.g., convection and radiation), 2) the root-mean-square error,

$$
\operatorname{RMSE}=\left[\frac{1}{N-1} \sum_{i=1}^{N}\left(\phi_{i}^{\prime}\right)^{2}\right]^{1 / 2},
$$

3) the ratio $\sigma_{\text {mod }} / \sigma_{\text {obs }}$ of modeled to observed standard deviations (referred to subsequently as "ratio"), 4) the standard deviation of the difference between the modeled and observed variables,

$$
\sigma_{\text {diff }}=\left[\frac{1}{N-1} \sum_{i=1}^{N}\left(\phi_{i}^{\prime}-\mathrm{MBE}\right)^{2}\right]^{1 / 2},
$$




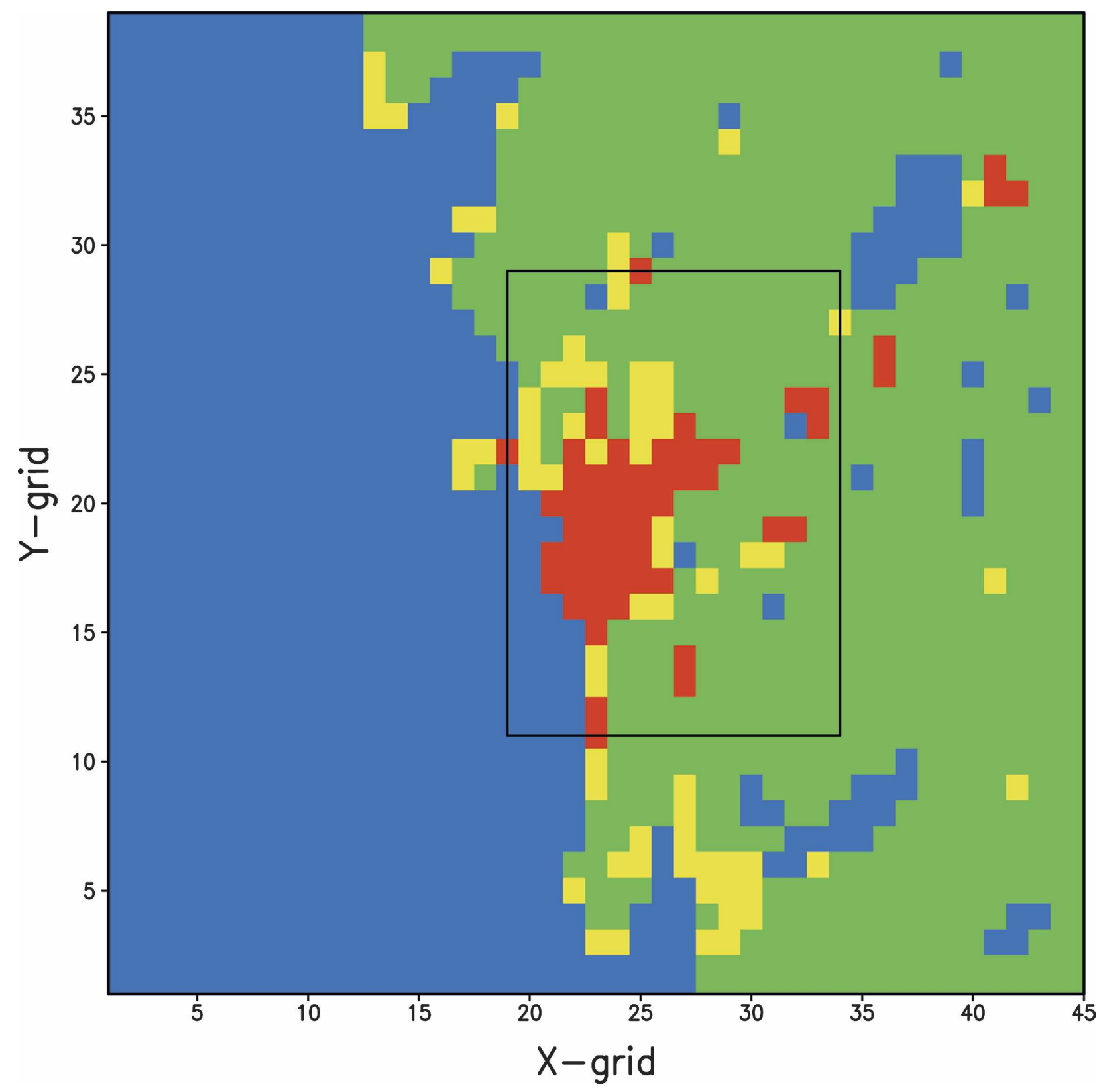

FIG. 2. Dominant land use category used in the innermost model domain (D4) with $2 \mathrm{~km} \times 2 \mathrm{~km}$ spacing. Red color denotes urban or built-up land (called urban for short), yellow cropland/grassland mosaic (crop), green evergreen needleleaf forest (forest), and dark blue water bodies (water, including sea and lake). The subdomain marked by the thick black line corresponds to the rectangle referred to in Fig. 1b (Tinytalk area).

which may indicate nonsystematic errors resulting from incorrect specification of model initial and boundary conditions or uncertainties in the observations [it also contains a component of natural observed variability because the model value is an average over a grid volume whereas the observed value is a discrete point measurement (Case et al. 2002)], and 5) the correlation coefficient $R$.
In the above formulas, $\phi_{i}^{\prime}$ is the departure of the modeled variables from the observed values at the $i$ th sampling point (i.e., modeled values minus observed values) and $N$ is the total sampling over space and time-that is, $N=m \times n$, in which $m$ is number of spatial points and $n$ is number of observational/forecast hours (temporal points). If $m=1$, the statistical measures are computed only over the temporal domain. 
TABLE 2. Summary of numerical experiments.

\begin{tabular}{llll}
\hline \hline Expt name & $\begin{array}{c}\text { Land surface } \\
\text { model }\end{array}$ & PBL scheme & $\begin{array}{c}\text { Soil moisture } \\
\text { initialization* }\end{array}$ \\
\hline Noah-Eta & Noah LSM & Eta PBL & ECMWF \\
Noah-MRF & Noah LSM & MRF PBL & ECMWF \\
PX-SMEC & Pleim-Xiu LSM & Pleim-Chang & ECMWF \\
& & PBL & \\
PX-SMLU & Pleim-Xiu LSM & Pleim-Chang & LANDUSE \\
& & PBL & \\
\hline
\end{tabular}

* ECMWF: soil moisture is initialized using ECMWF data; LANDUSE: soil moisture is initialized using climatological values based on vegetation type (land use category) and season (summer and winter).

\section{Results and discussion}

\section{a. Mean hourly near-surface air temperature}

To identify the overall model performance on nearsurface air temperature, Fig. 3 shows the time series of modeled and observed near-surface air temperature averaged over all the observational sites. As seen from Fig. 3, all schemes can simulate the phase of the diurnal cycle well (high $R$ values) but underestimate the amplitude of the diurnal cycle. The difference between modeled and observed results varies daily, depending on the synoptic situations. Among the four schemes, Noah LSM (Figs. 3a,b) is generally worse than PleimXiu LSM (Figs. 3c,d) in predicting near-surface air temperature. Comparison between Fig. $3 \mathrm{a}$ and Fig. $3 \mathrm{~b}$ shows that the difference between the two PBL schemes (Eta and MRF) coupled with Noah LSM is not evident, but the Eta PBL scheme has higher skill than the MRF PBL scheme. The difference between Fig. 3c and Fig. 3d indicates that soil moisture initialization plays an important role. Soil moisture for PX-SMEC is initialized by interpolating large-scale model output (ECMWF), while PX-SMLU is initialized using climatological values based on vegetation type. It is clear that the PX-SMLU scheme performs better than the PX-
SMEC scheme. This is partly because PX-SMLU uses more reasonable soil moisture initialization in terms of spatial distribution.

\section{b. Diurnal heating and diurnal cycle}

To examine the ability of LSMs to simulate diurnal heating, diurnal cycle intensity (DCI), which is defined as the difference between daily maximum and minimum near-surface air temperatures, is used in this study. Figure 4 shows the modeled versus observed DCIs with different schemes. All schemes underestimate DCI, with a range of $2.5^{\circ}-5.0^{\circ} \mathrm{C}$. Among these four schemes, the PX-SMLU scheme with soil moisture using climatological values performs best in estimating DCI, while the other three schemes display similar performance. The underestimate of DCI (Fig. 4) is partly due to the underestimate of maximum temperature during the daytime and the overestimate of minimum temperature during the nighttime (Fig. 3), especially under clear sky conditions (7-12 May 2001). Also, Figs. 3 and 4 indicate that the performance of all schemes in simulating DCI changes from day to day and strongly depends on weather conditions. Statistical measures of modeled daily maximum (Tmax) and minimum (Tmin) temperatures with different schemes are presented in Fig. 5. The figure shows that all schemes underestimate daily maximum temperature but overestimate daily minimum temperature. Near-surface air temperature is mainly controlled by the surface energy budget, especially the sensible heat during the day and outgoing longwave radiation during night. The underestimated daytime temperatures indicate that the models either underestimate the absorbed solar radiation at the surface or underestimate the upward sensible heat flux. For the nighttime temperature, the balance between the outgoing radiation and upward heat release from the underlying surface determines the change of the temperature. Thus, the overestimate is an indication that either the longwave radiation is underestimated or

TABLE 3. Vegetation-related physical parameters used in Noah LSM (MM5, version 3.7.2). LUC (land use category), SHDFAC (green vegetation fraction), and Rsmin (min stomatal resistance). Only the LUCs in D4 are listed.

\begin{tabular}{rcccccr}
\hline \hline LUC & Vegetation description $^{\mathrm{a}}$ & Albedo $(\%)$ & Emissivity $(\%$ at $9 \mu \mathrm{m})$ & Roughness length $(\mathrm{cm})$ & SHDFAC $^{\mathrm{b}}$ & Rsmin $\left.^{(\mathrm{s} \mathrm{m}}{ }^{-1}\right)$ \\
\hline 1 & Urban $^{\mathrm{c}}$ & 15 & 88 & 80 & 0.05 & 400 \\
5 & Crop & 18 & 99 & 14 & VEGFRC & 40 \\
14 & Forest & 12 & 95 & 50 & VEGFRC & 125 \\
16 & Water & 8 & 98 & 0.01 & VEGFRC & - \\
\hline
\end{tabular}

${ }^{a}$ Urban: urban and built-up land; crop: cropland/grassland mosaic; forest: evergreen needleleaf forest; and water: water bodies.

${ }^{\mathrm{b}}$ VEGFAC: monthly climatological green vegetation (Chen and Dudhia 2001a) data.

${ }^{c}$ CSOIL (volumetric heat capacity) and DF1 (soil thermal conductivity) for urban surface are set to $3.0 \times 10^{6} \mathrm{~J} \mathrm{~m}^{-3} \mathrm{~K}^{-1}$ and $3.24 \mathrm{~W}$ $\mathrm{m}^{-1} \mathrm{~K}^{-1}$, respectively (Chen et al. 2004). 
TABLE 4. Vegetation-related physical parameters used in Pleim-Xiu LSM: $Z_{0}$ (roughness length), $\operatorname{MnFr}$ [min vegetation fraction $(\%)$ ], MxFr [max vegetation fraction (\%)], MnLA (min LAI), MxLA (max LAI), and Rsmin (min stomatal resistance). Only LUCs in D4 are listed. Vegetation growth is represented using the interpolated LAI and vegetation fraction between max and min values for each grid cell from monthly VEGFRC data (cf. Table 3). Emissivity listed in Table 3 is also used in Pleim-Xiu LSM.

\begin{tabular}{rccccccrr}
\hline \hline LUC & Vegetation description* & $Z_{0}(\mathrm{~cm})$ & $\mathrm{MnFr}$ & $\mathrm{MxFr}$ & $\mathrm{MnLA}$ & $\mathrm{MxLA}$ & $\mathrm{Rsmin}^{\left(\mathrm{s} \mathrm{m}^{-1}\right)}$ & SLMO** $^{* *}$ \\
\hline 1 & Urban & 50 & 20 & 40 & 0.05 & 2.0 & 150 & 0.10 \\
5 & Crop & 10 & 35 & 95 & 1.0 & 2.5 & 80 & 0.25 \\
14 & Forest & 50 & 80 & 90 & 3.0 & 4.0 & 175 & 0.30 \\
16 & Water & 0.001 & - & - & - & - & - & 1.00 \\
\hline
\end{tabular}

* Refer to the notes of Table 3 .

** SLMO: surface moisture availability (fraction), which is only used in PX-SMLU experimental scheme for initialization (cf. notes of Table 2).

the heat flux from the underlying surface is overestimated. Unfortunately, since there was no detailed energy budget measured during the study period, the real cause behind the differences cannot be speculated.

\section{c. Urban heat island}

The urban effect on temperature, wind, and humidity in the PBL is important for mesoscale models applied at fine scales. Improper parameterization of urban land use results in bias in forecasted boundary layer variables, and further, in predicting the temperature and wind fields (Chen et al. 2004). The urban heat island (UHI) is characterized by urban warming relative to the surrounding rural areas and is the most salient feature of urbanization.

Over the last few years, some efforts have been made to include the urban effect in MM5 in order to improve the model's performance in urban climate applications (e.g., Zehnder 2002; Chen et al. 2004; Otte et al. 2004; Mölders and Olson 2004; Dupont et al. 2004; Fan and Sailor 2005; Grossman-Clarke et al. 2005; Dandou et al. 2005). These studies show that the modeling of urban effect is dependent on the 1) implementation of urban canopy parameterization schemes in the model and 2) representation of land use characteristics for urban categories such as albedo, heat capacity, and roughness. In this study, it is examined how UHI is modeled by the MM5 with different LSM parameterizations. For this purpose, we select the 9 urban sites and the 20 rural sites out of the 29 observation sites based on the modelresolved dominant LUCs in D4 (Fig. 2), and compute the averaged urban-rural air temperature difference for the modeled and observed results as an indicator of UHI intensity.

Figure 6a shows the time series of the modeled and observed UHI intensity. Generally, Noah LSM predicts the presence and amplitude of UHI reasonably well, while Pleim-Xiu LSM can only capture the presence of UHI but clearly underestimates its strength. This is partly due to the fact that Noah LSM includes the urban effect by incorporating a bulk parameterization for urban land use (Chen et al. 2004; Liu et al. 2006) in MM5 (cf. Table 3), while Pleim-Xiu LSM (Xiu and Pleim 2001) does not explicitly include the urban effect. The latter means that Pleim-Xiu LSM does not have special parameterization for urban land use, although urban effect is dealt with only by regarding urban (or built-up land) as one of 25 land use types. Figure $6 \mathrm{~b}$ presents UHI intensity and frequency of occurrence for modeled and observed UHIs with different schemes during daytime and nighttime under different weather conditions. For Noah LSM, its coupling with Eta and MRF PBL schemes displays similar performance in predicting UHI, especially under clear sky conditions.

Figure 7 shows the diurnal cycle of near-surface temperature MBE with different schemes for urban and rural sites. Interestingly, most schemes underestimate near-surface air temperature during the daytime but overestimate it during the nighttime. For Noah LSM, it shows no evident difference in MBE between urban and rural sites, whereas the Pleim-Xiu LSM shows a slight difference between them, especially for the PXSMLU scheme. The MBE for the PX-SMLU scheme has a different sign during the afternoon in the rural area than in all of the other simulations.

\section{d. Spatial distributions}

Figures 8 and 9 show the spatial distribution of nearsurface air temperature simulated by different schemes over one subdomain in D4, and the observed 2-m air temperature ("Tinytalk OBS") over the corresponding area. It is found that 1) during the daytime under the high pressure system, Noah-Eta and Noah-MRF simulate the urban effect fairly well, and PX-SMEC can also recognize this feature, but all three schemes underestimate the near-surface temperature over the urban area by approximately $1^{\circ}-2^{\circ} \mathrm{C}$. PX-SMLU cannot recognize the presence of UHI (Fig. 8a); 2) during the nighttime 
NOAH-ETA

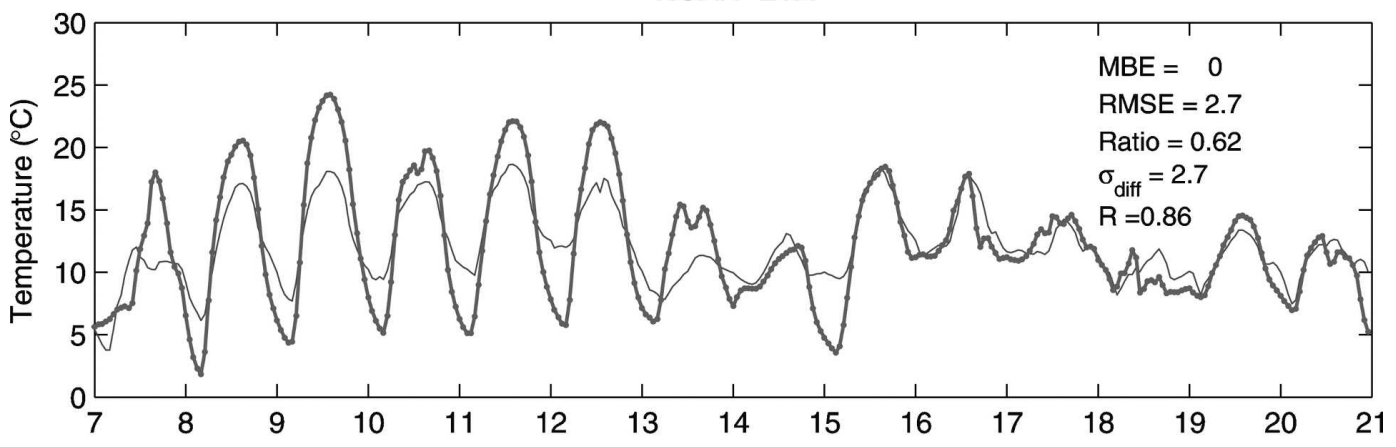

NOAH-MRF

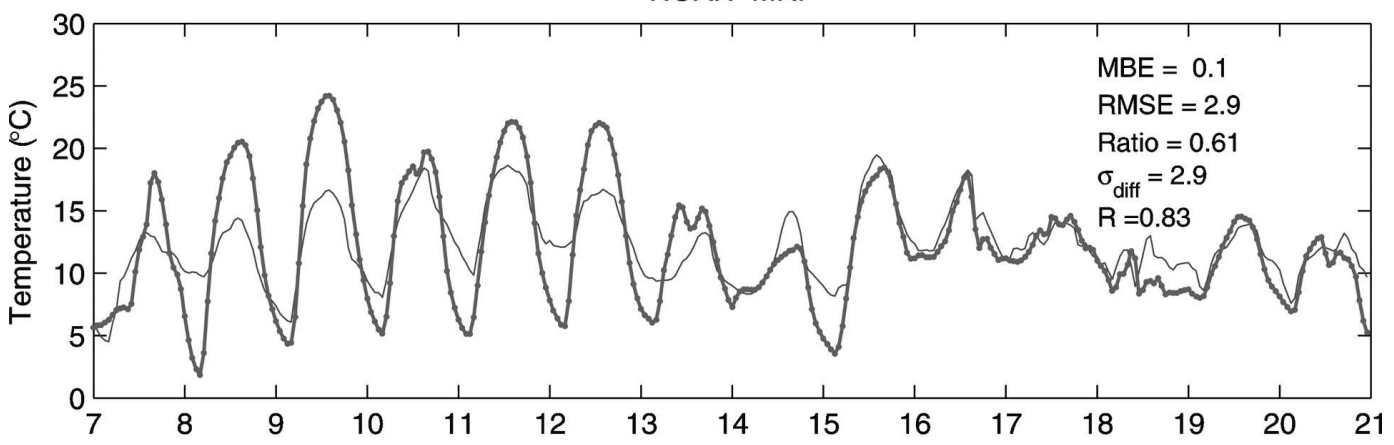

PX-SMEC

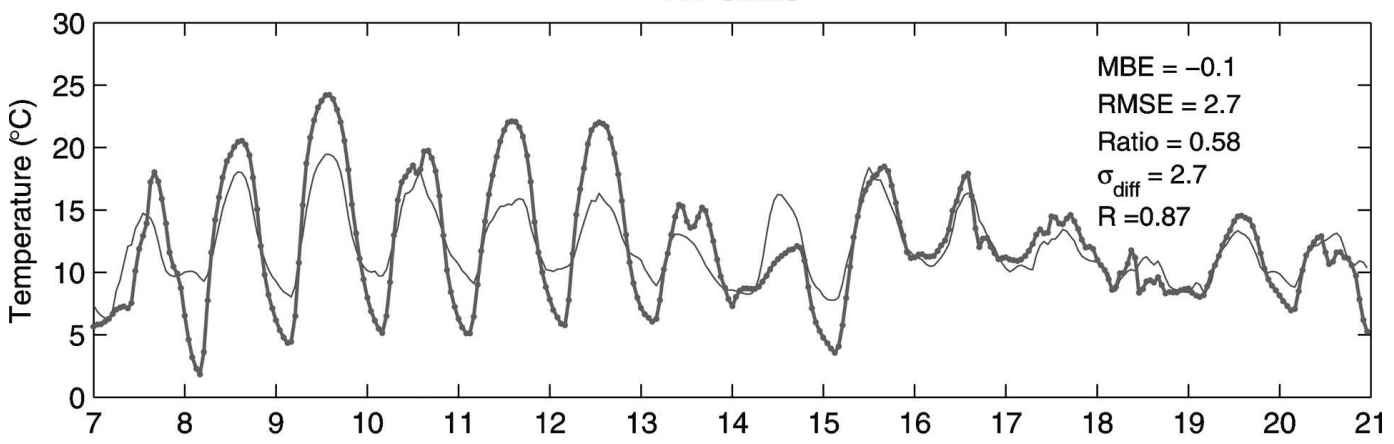

PX-SMLU

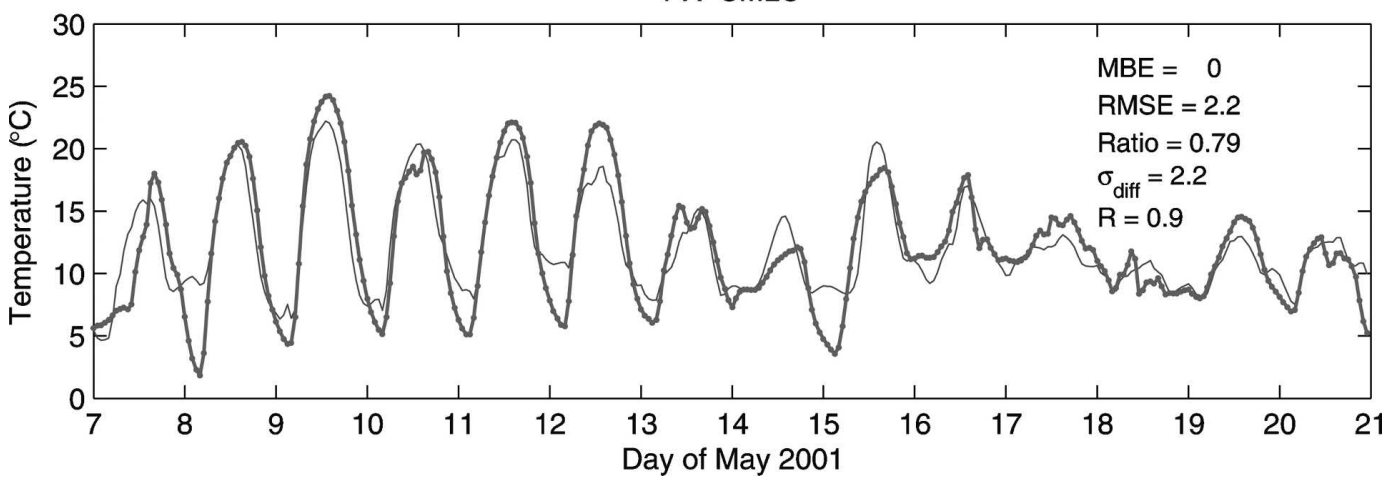

FIG. 3. Observed (thick dotted line) and modeled (solid thin line) hourly near-surface air temperature averaged over the 29 observational sites with different experiment schemes from 0000 UTC 7 to 2300 UTC 20 May 2001. Observed near-surface air temperature is measured at $2 \mathrm{~m} \mathrm{AGL}$. Modeled near-surface air temperature is at $2 \mathrm{~m}$ AGL for Noah-Eta and Noah-MRF and at $1.5 \mathrm{~m}$ AGL for PX-SMEC and PX-SMLU. The modeled results are bilinearly interpolated to the observational sites. The statistical parameters are given within the plot (sample number $N=336$ ). 

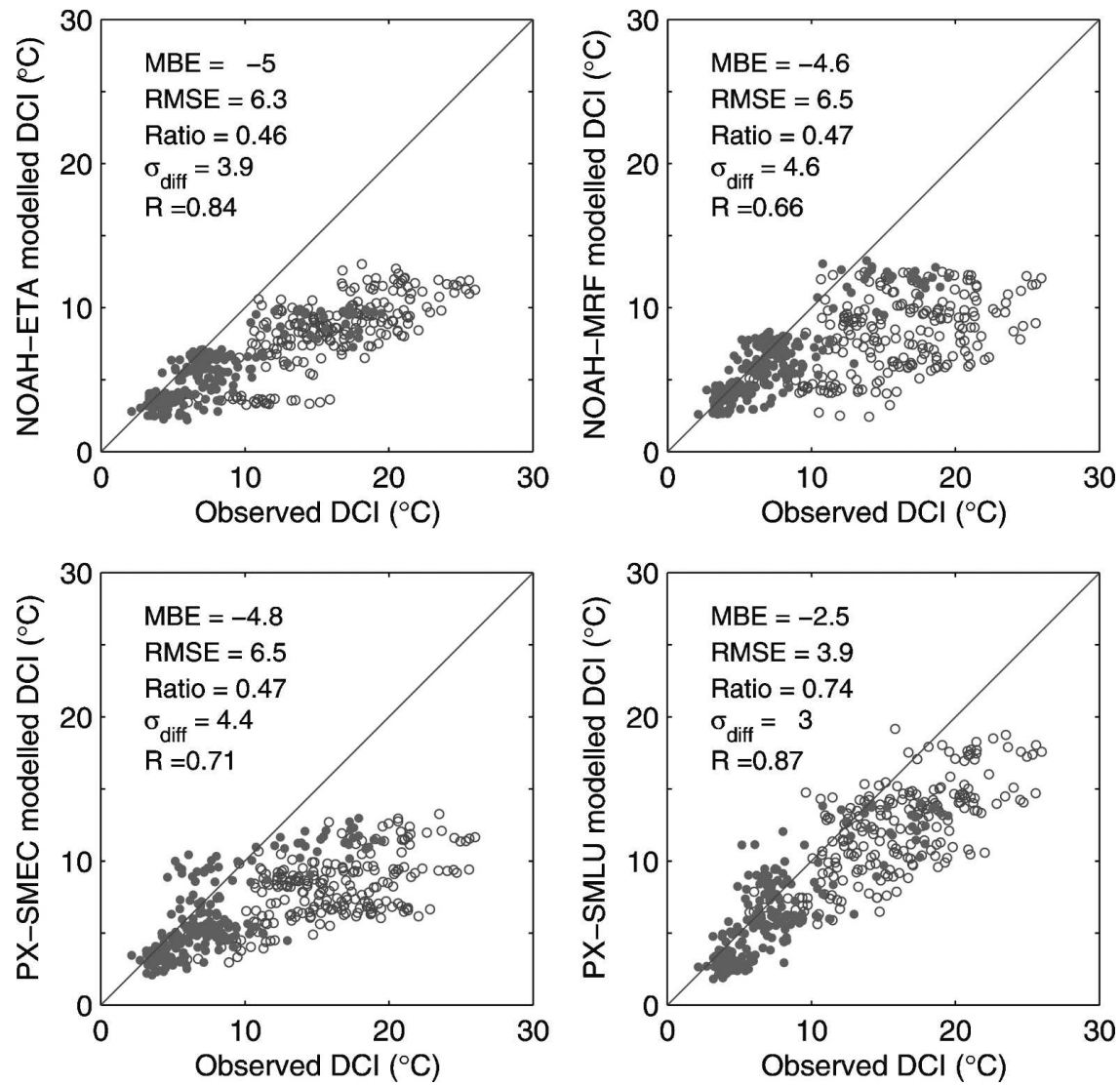

FIG. 4. Scatterplot of observed vs modeled DCI with different experiment schemes. The results are based on daily maximum and minimum near-surface air temperature during the period 7-20 May 2001 over the 29 observational sites. The statistical parameters are presented within the plot (temporal sample number: $n=14$; spatial sample number: $m=29$ ). The DCI for the first week (W1; 7-13 May 2001) and the second week (W2; 14-20 May 2001) is denoted by open circles and filled circles, respectively, to distinguish differences in weather conditions.

under the high pressure system, Noah LSM can simulate the presence of UHI but overestimates the nearsurface temperature over the urban area by about $2^{\circ} \mathrm{C}$, whereas Pleim-Xiu LSM cannot reproduce the observed UHI. The observed nighttime surface temperature is found to be very sensitive to land use variations, but the modeled results are less sensitive to the variations. All schemes cannot simulate the low values of the temperature well in the mountain-valley contrast area (Fig. 8b; cf. Fig. 1b); 3) during the daytime under the low pressure system, Noah LSM simulates the presence of UHI well but overestimates the near-surface air temperature over the urban area by $1^{\circ}-2^{\circ} \mathrm{C}$, while PleimXiu LSM simulates the presence of UHI to some extent (Fig. 9a); and 4) during the nighttime under the low pressure system, Noah LSM exaggerates the UHI, while Pleim-Xiu LSM can simulate the presence of weak UHI (Fig. 9b). The above results suggest that the model performance in simulating the effects of land cover and surface characteristics on near-surface air temperature (e.g., UHI) is dependent on daytime/ nighttime and weather conditions, as well as on the LSMs used.

\section{e. Surface energy fluxes}

Tables 5 and 6 present the surface energy fluxes [sensible heat flux ( $\mathrm{SH})$, latent heat flux ( $\mathrm{LH})$, and soil heat flux $G$ ] averaged over different LUCs during daytime and nighttime for the two distinct weather conditions, respectively. Under fine weather conditions (clear-sky days), the simulated SH over the vegetated surfaces (urban, crop, and forest) during the day with the PXSMLU scheme is clearly larger than that with the Noah-Eta, Noah-MRF, and PX-SMEC schemes, respectively. This likely contributed to the relatively high skill of the PX-SMLU scheme in predicting maximum temperature (cf. Fig. 5). Noah LSM has positive sensible heat flux during the night over the urban area, 

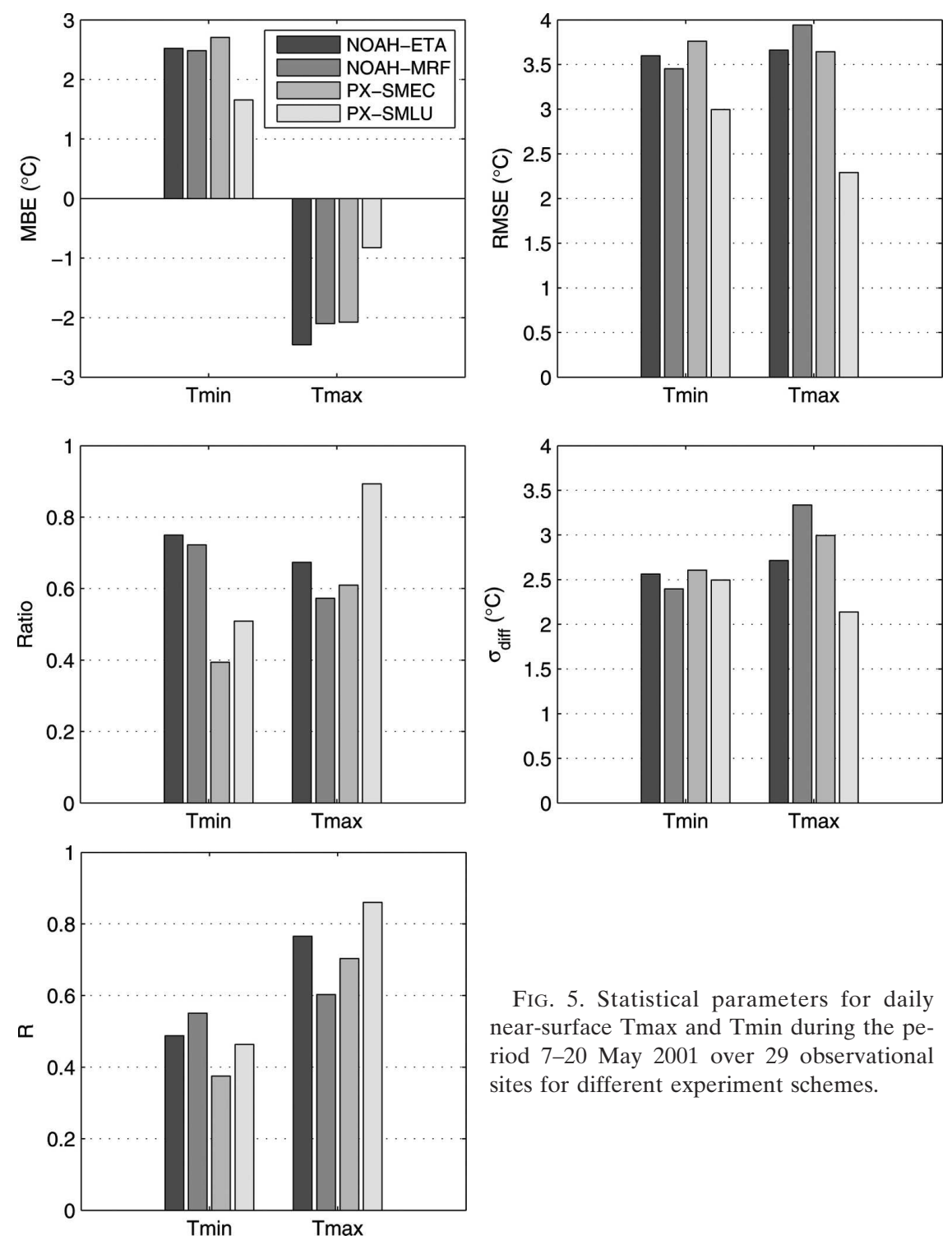

FIG. 5. Statistical parameters for daily near-surface Tmax and Tmin during the period 7-20 May 2001 over 29 observational sites for different experiment schemes.

whereas Pleim-Xiu LSM has negative sensible heat flux. This may be associated with the fact that Noah LSM has explicit urban parameterization. The increased daytime heat storage in the urban area results in a positive nighttime sensible heat flux. The soil heat flux $G$ during the nighttime over the vegetated surfaces displays different signs between Noah LSM and PleimXiu LSM. Under cloudy and rainy conditions, Noah LSM gives higher sensible heat flux than PX LSM over the urban area during the day. This most likely contributed to the overestimated near-surface air temperature over the urban area with Noah LSM. During the night, Noah LSM and Pleim-Xiu LSM have opposite signs in estimating sensible heat flux over the urban area. Soil heat fluxes simulated with Noah LSM and Pleim-Xiu
LSM are also opposite in sign. During the whole period, the latent heat flux over the urban area simulated with Noah LSM is generally less than that simulated with Pleim-Xiu LSM, which helps explain the difference in modeling UHI between Noah LSM and Pleim-Xiu LSM.

\section{f. Sensitivity to screen height}

As mentioned in section 2a(2), the coupled MM5 and Pleim-Xiu LSM model outputs 1.5-m (AGL) air temperature. This is based on the fact that the screen height is set to $1.5 \mathrm{~m}$ (default) in Pleim-Xiu LSM. In the above study, the observed 2-m air temperature is used to compare with the modeled $1.5-\mathrm{m}$ air temperature for the experiments related to Pleim-Xiu LSM (PX-SMEC 
(a)
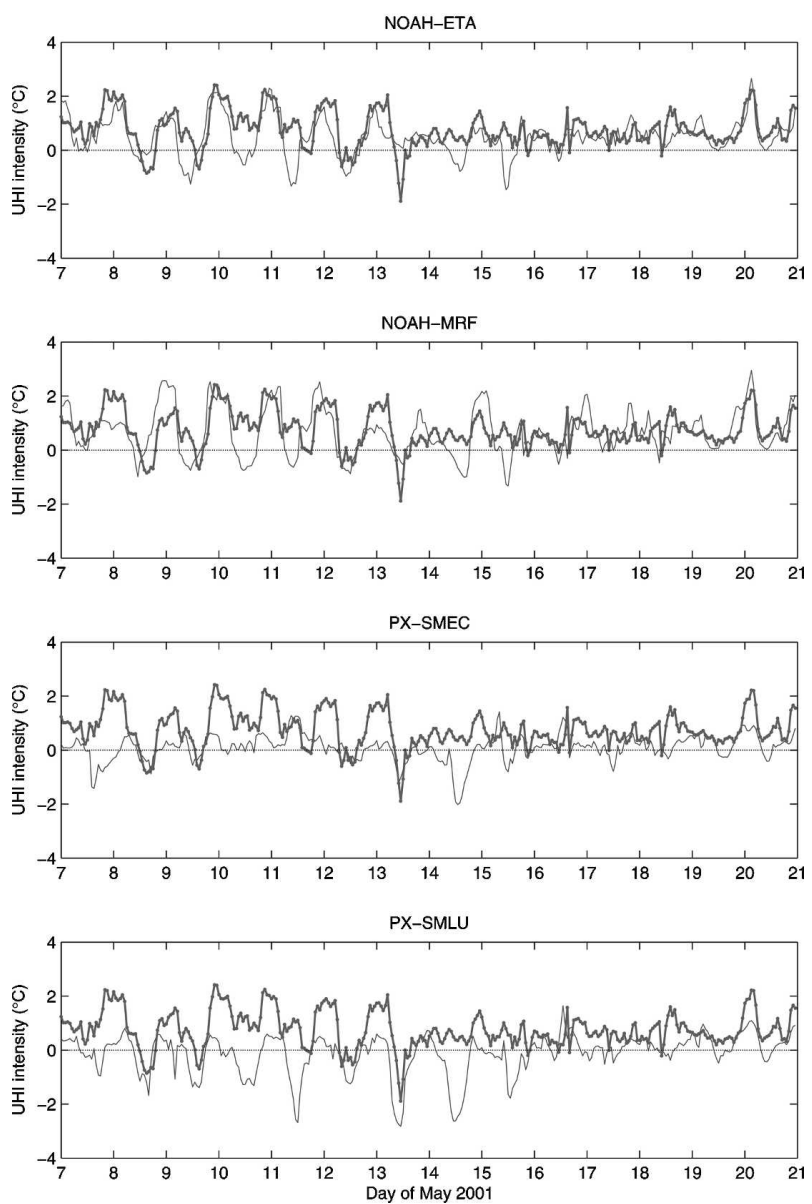

and PX-SMLU). Obviously, this invokes the question: Does inconsistency in screen heights for observed and modeled near-surface air temperatures introduce a bias into the analysis? Theoretically, it would introduce a bias, as large vertical temperature gradients may exist in the lowest layer of the atmosphere. To evaluate the difference caused by different screen heights, we repeated the PX-SMEC experiment using 2-m screen height in Pleim-Xiu LSM, instead of the default value $(1.5 \mathrm{~m})$. The scatterplot of 1.5 - versus 2 -m air temperature (which is, respectively, output from the experiment results using 1.5 and $2.0 \mathrm{~m}$ as the screen height) over 29 sites during 7-20 May 2001 is shown in Fig. 10. The result shows that the difference is statistically significant at the $95 \%$ confidence level ( $t$ test). The difference between the temperatures at 1.5 and $2.0 \mathrm{~m}, T_{1.5 \mathrm{~m}}-$ $T_{2.0 \mathrm{~m}}$, is $-1.1^{\circ} \mathrm{C}$ during daytime and $0.4^{\circ} \mathrm{C}$ during nighttime. The performance statistics of PX-SMEC experiments using different screen heights $(1.5$ and $2.0 \mathrm{~m})$ are summarized in Table 7. Relative to using 1.5-m screen height, the statistical measures of PX-SMEC using 2-m (b)
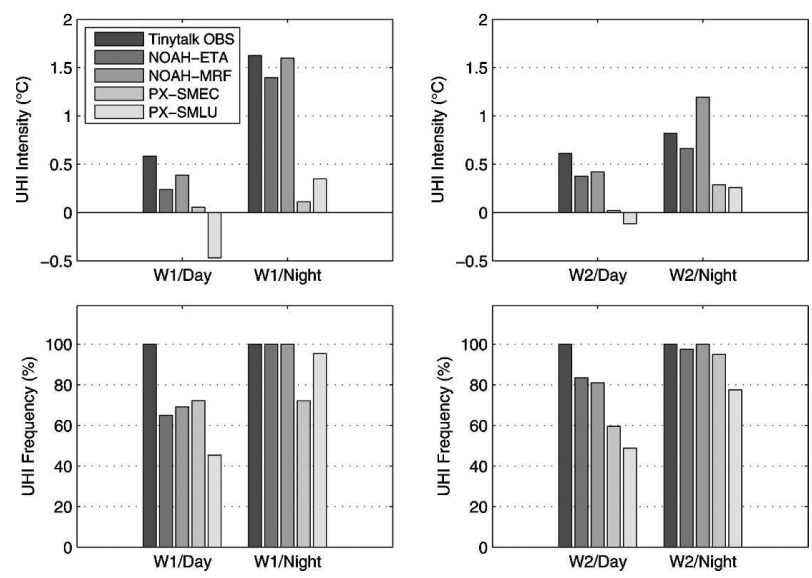

FIG. 6. (a) Hourly variation of observed (thick dotted line) and modeled (solid thin line) UHI intensity during the period from 0000 UTC 7 to 2300 UTC 20 May 2001 for different experiment schemes. The UHI intensity is defined as the difference between averaged near-surface air temperatures over urban and rural sites for observational measurements (9 urban sites, 20 rural sites). (b) Observed and modeled mean UHI (top) intensities and (bottom) frequencies during daytime and nighttime for (left) the first week (W1) and (right) second week (W2). Modeled UHI frequency is defined as a percentage of occurrence of the modeled UHI $>0$ when observed UHI $>0$ during a certain period, while the observed UHI frequency is set to $100 \%$ in this case.

screen height show small biases or errors in overall performance as expected, being characterized by increased ratio from 0.58 to 0.88 , decreased $\sigma_{\text {diff }}$ from $2.7^{\circ}$ to $2.1^{\circ} \mathrm{C}$, and higher $R$ in hourly near-surface air temperature TS (Table 7). The bias or error of DCI is clearly decreased: $\mathrm{MBE}$ drops by $3.4^{\circ} \mathrm{C}$ while ratio increases to 0.81 from 0.47 , and $\sigma_{\text {diff }}$ is lower. Also, the biases or errors of daytime maximum temperature and nighttime minimum temperature are clearly decreased (Table 7).

\section{g. Version 3.7.2 versus version 3.7.3}

The above results are based on version 3.7.2 of MM5. On 21 November 2005, a newer version of MM5, version 3.7.3, was released (documented online at http:// www.mmm.ucar.edu/mm5/mm5v3/v3mm5-chg-v37.html) and became the latest version of MM5 as of this writing. In this version, some modifications to surface longwave radiation parameterizations in Noah LSM are made, and some adjustments to parameter values for the vegetation properties are also done. The difference 

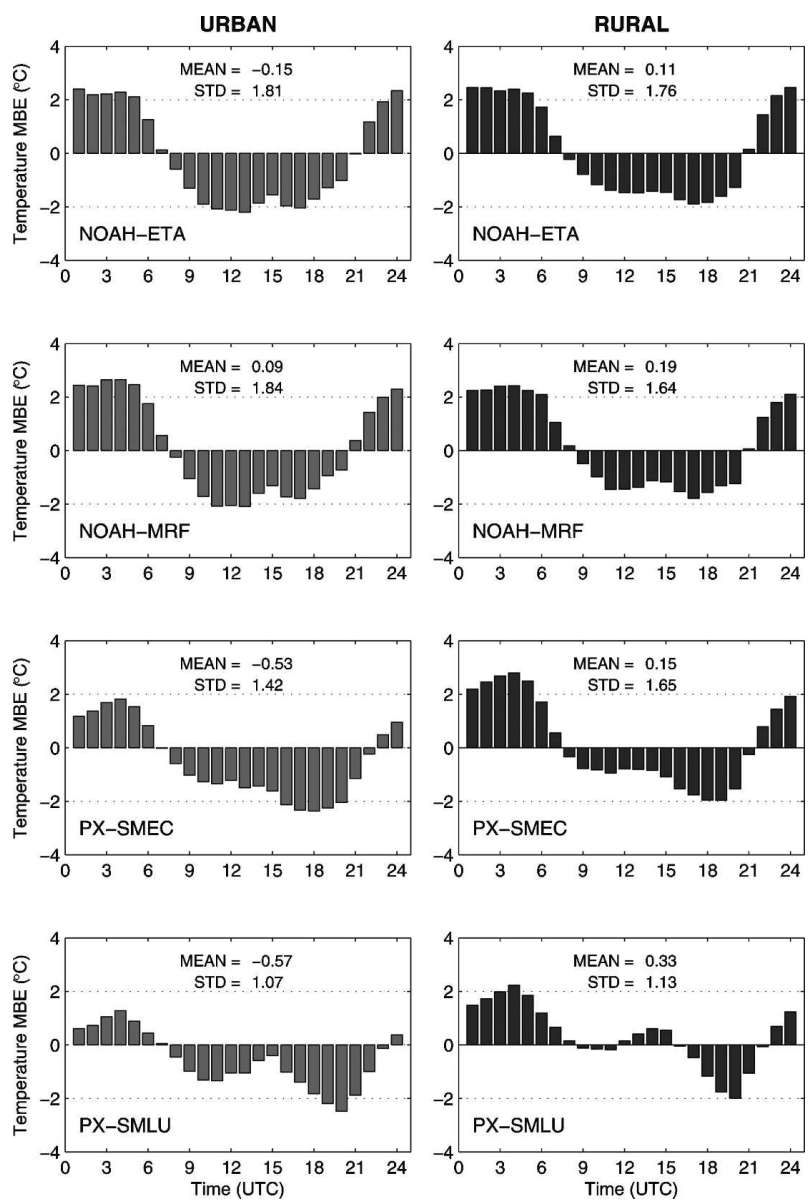

FIG. 7. Diurnal variation of MBE of near-surface air temperature with different experiment schemes for (left) urban sites (9) and (right) rural sites (20) during the period 7-20 May 2001, at which the measurements were done. The mean value (MEAN) and std dev (STD) of diurnal MBE are presented within the plot.

between these two versions in Noah LSM is presented in Table 8 , and that in vegetation parameter is given in Table 9. It is noted that the emissivity in Table 9 (also in Table 3) is not only used in Noah LSM, but also in Pleim-Xiu LSM, and therefore the changes in the emissivity might affect the simulated results with these two LSMs.

To examine the difference between using version 3.7.2 and version 3.7.3 in simulating near-surface air temperature with Noah and Pleim-Xiu LSMs, respectively, two additional numerical experiments are performed using version 3.7.3: Noah-Eta_V3.7.3 and PXSMEC_V3.7.3. The Noah-Eta_V3.7.3 is the same as the Noah-Eta in Table 2 but different in the parameterizations for upward/downward longwave radiation (Table 8) and in vegetation parameters (Table 9), while the PX-SMEC_V3.7.3 is the same as the PX-SMEC in Table 2 but different in the emissivity presented in Table 9. For the convenience of discussions, we here- inafter refer to Noah-Eta and PX-SMEC in Table 2 as Noah-Eta_V3.7.2 and PX-SMEC_V3.7.2, respectively. For Pleim-Xiu LSM, the emissivity effect is included in the net longwave radiation computation at ground: $-\varepsilon\left(\sigma T_{\frac{4}{8}}-\mathrm{GLW}\right)$. Here, $\varepsilon$ is the emissivity, $\sigma$ is the Stefan-Boltzmann constant, $T_{g}$ is the ground temperature, and GLW is the longwave downward component of the flux at ground. The performance statistics of the Noah-Eta and PX-SMEC experiments using two different versions (versions 3.7.2 and 3.7.3) are summarized in Table 10.

\section{1) NoAh-Eta EXPERIMENTS}

Relative to version 3.7.2, the statistical measures of Noah-Eta for version 3.7.3 show some improvements in overall performance, characterized by increased ratio, decreased $\sigma_{\text {diff }}$, and higher $R$ in TS (Table 10). The prediction of DCI is clearly improved: MBE drops by about $1^{\circ} \mathrm{C}$ while ratio increases from 0.46 to 0.56 , and $\sigma_{\text {diff }}$ is lower. The better performance for estimating DCI using version 3.7 .3 is mainly due to the evident improvement in predicting nighttime minimum temperature. The daytime maximum temperature shows no improvement (Table 10). This implies that the parameterization of longwave radiation is crucial only to estimating minimum temperature.

To separate the above combined effect of downward longwave radiation, upward longwave radiation, and vegetation parameters for Noah-Eta using version 3.7.3 (Tables 8 and 9), two sensitivity experiments are carried out in this study to investigate the individual effect of downward longwave radiation and upward longwave radiation on simulated results, respectively. The sensitivity experiment that was the same as Noah-Eta_V3.7.2 but only considering the emissivity effect in the parameterization of downward longwave radiation suggests that both the maximum temperature and minimum temperature have some improvements, but the improvement is not significant. In contrast, the sensitivity experiment that was the same as Noah-Eta_V3.7.2 but using air temperature at the first model level above ground instead of using skin temperature for the parameterization of upward longwave radiation indicates that the minimum temperature has evident improvements. For example, MBE decreases from $2.5^{\circ}$ to $1.8^{\circ} \mathrm{C}$, $\sigma_{\text {diff }}$ decreases from $2.6^{\circ}$ to $2.4^{\circ} \mathrm{C}$, and $R$ increases from 0.49 to 0.56 , while the maximum temperature has no improvement and is even a little worse in the performance statistics.

\section{2) PX-SMEC EXPERIMENTS}

The only difference between version 3.7.2 and version 3.7.3 for Pleim-Xiu LSM is the change in emissiv- 
(a)
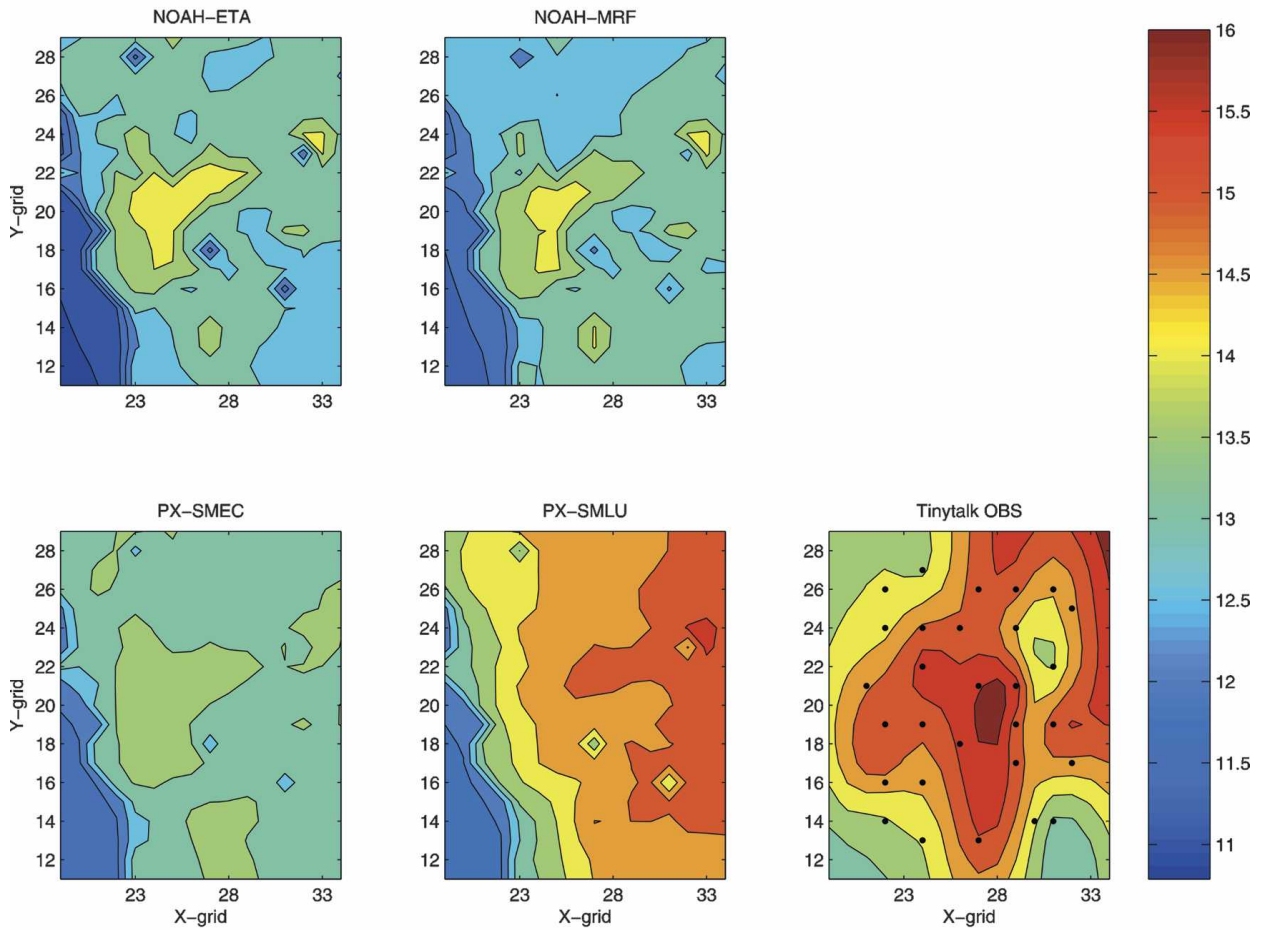

(b)
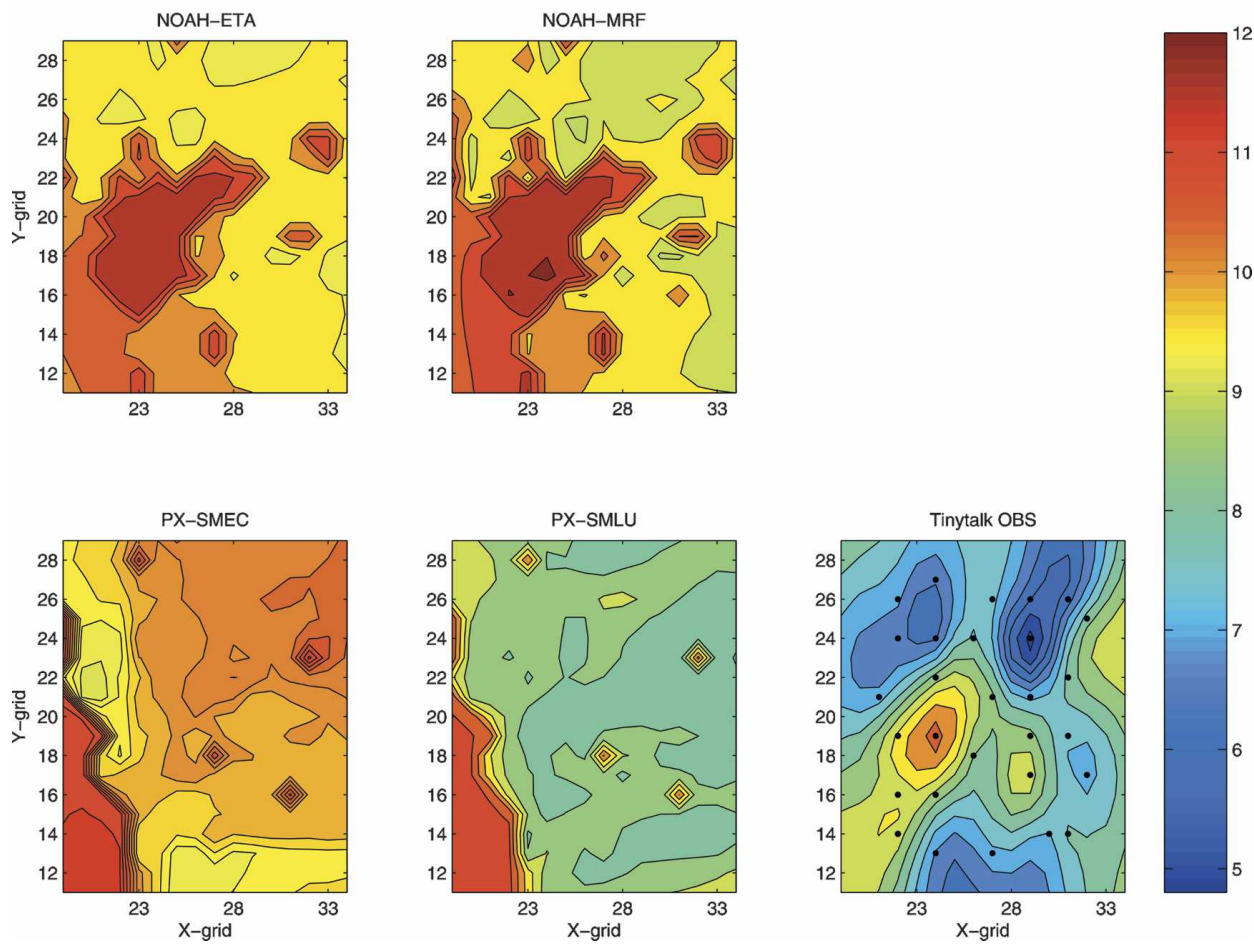

FIG. 8. Spatial distribution of observed and modeled near-surface air temperatures $\left({ }^{\circ} \mathrm{C}\right)$ averaged during the first week (W1) for (a) daytime and (b) nighttime over the Tinytalk area (cf. the subdomain in Fig. 2). The observed field (Tinytalk OBS) is derived from the interpolation of surface air temperature from the observational sites to model grids using the Griddata method (Sandwell 1987) and bilinear method. 
(a)
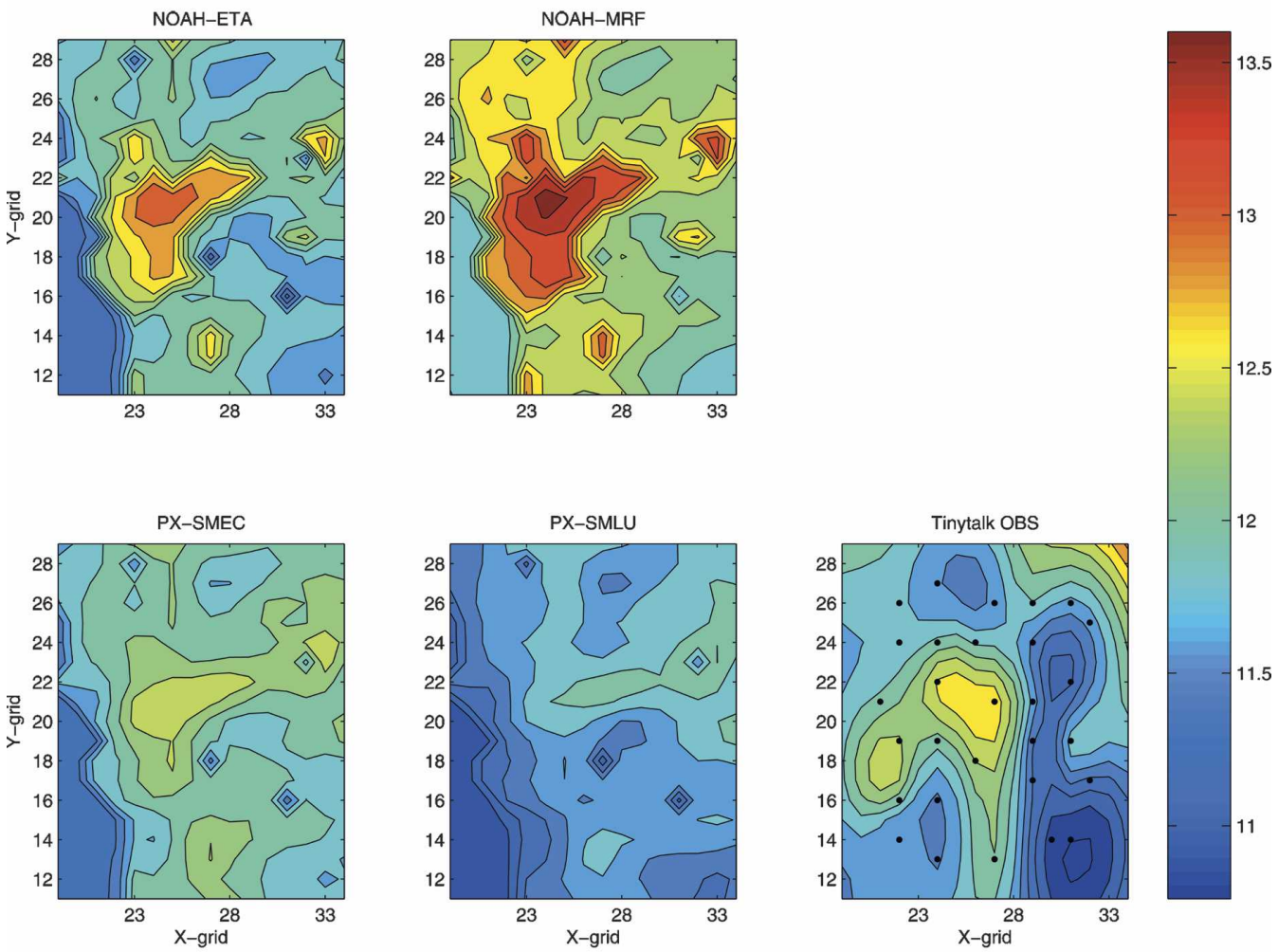

(b)
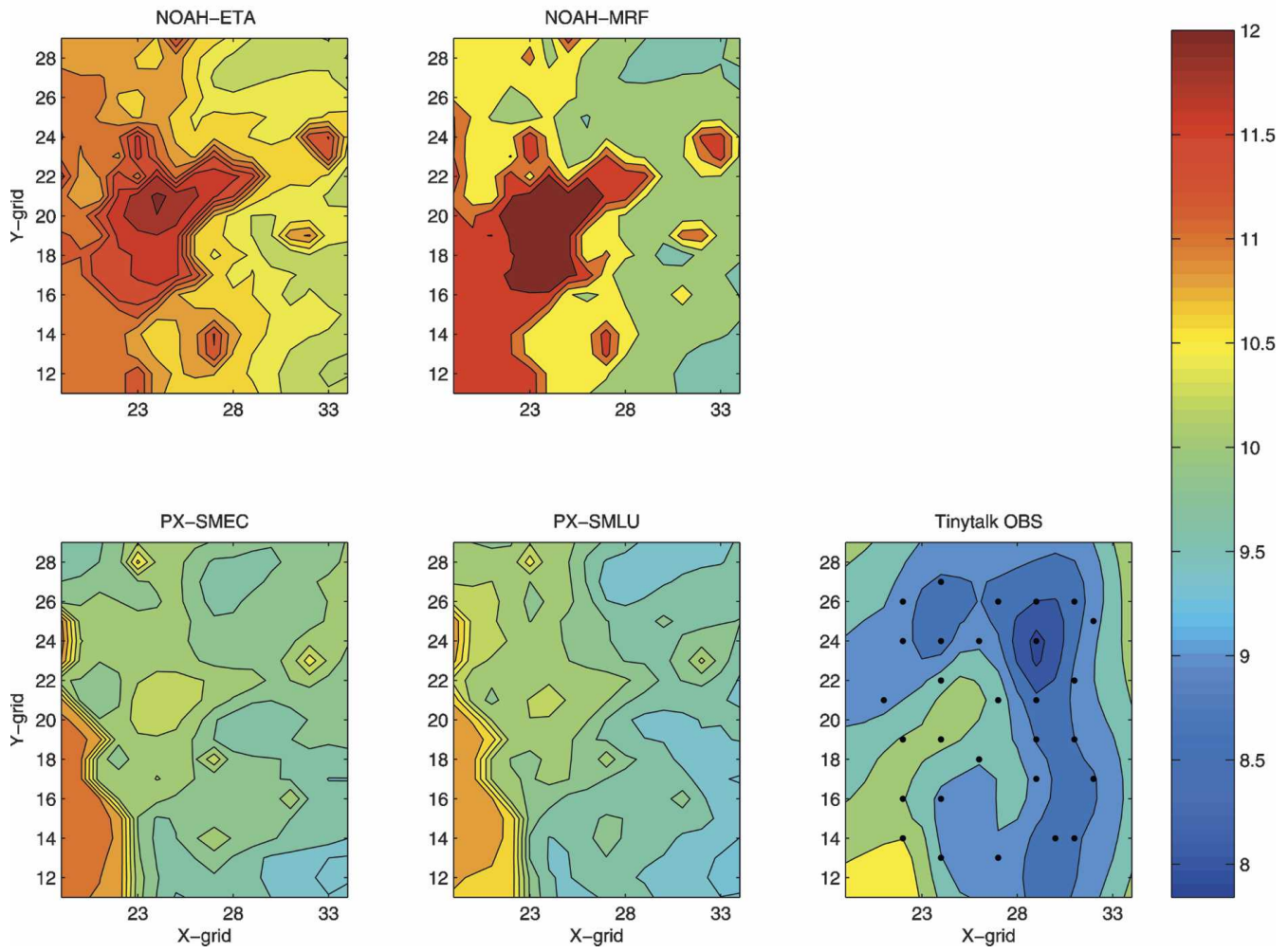

FIG. 9. As in Fig. 8, but for the second week (W2). 
TABLE 5. Mean SH, LH, and $G$ modeled by different experiment schemes for different dominant LUC over D4 domain for daytime and nighttime during the period 7-13 May 2001 (clear-sky days). Statistical parameters are based on hourly data during the period. Sample number $N=m \times n ; m$ represents spatial points, depending on LUCs, and $n$ represents temporal points.

\begin{tabular}{|c|c|c|c|c|c|c|c|c|c|}
\hline \multirow[b]{2}{*}{ LUC } & \multirow[b]{2}{*}{ Flux $\left(\mathrm{W} \mathrm{m}^{-2}\right)$} & \multicolumn{2}{|c|}{ Noah-Eta } & \multicolumn{2}{|c|}{ Noah-MRF } & \multicolumn{2}{|c|}{ PX-SMEC } & \multicolumn{2}{|c|}{ PX-SMLU } \\
\hline & & Day & Night & Day & Night & Day & Night & Day & Night \\
\hline \multirow[t]{3}{*}{ Urban $(m=57)$} & $\mathrm{SH}$ & 127 & 13 & 133 & 16 & 124 & -13 & 168 & -17 \\
\hline & $\mathrm{LH}$ & 0 & 0 & 0 & 0 & 36 & 8 & 13 & 0 \\
\hline & $G$ & -62 & 46 & -63 & 41 & 25 & -28 & 17 & -23 \\
\hline \multirow[t]{3}{*}{ Crop $(m=69)$} & $\mathrm{SH}$ & 63 & -16 & 65 & -12 & 82 & -11 & 121 & -15 \\
\hline & $\mathrm{LH}$ & 78 & -1 & 80 & -1 & 63 & 3 & 39 & 1 \\
\hline & $G$ & -20 & 24 & -20 & 23 & 21 & -31 & 18 & -28 \\
\hline \multirow{3}{*}{ Forest $(m=810)$} & $\mathrm{SH}$ & 72 & -14 & 78 & -10 & 80 & -12 & 134 & -17 \\
\hline & LH & 96 & 4 & 100 & 3 & 87 & 6 & 52 & 1 \\
\hline & $G$ & -22 & 24 & -22 & 22 & 23 & -30 & 21 & -27 \\
\hline \multirow[t]{2}{*}{ Water $(m=819)$} & $\mathrm{SH}$ & 12 & 1 & 6 & -1 & 3 & -2 & 2 & -1 \\
\hline & LH & 63 & 27 & 50 & 25 & 26 & 11 & 23 & 17 \\
\hline
\end{tabular}

ity (Table 9), which affects downward and upward longwave radiations at ground, and thus net longwave radiation. This effect is dependent on vegetation type and divided into indirect and direct ones on simulated results in D4. The direct effect is caused by the resolved LUCs in D4, while the indirect effect resulted from atmospheric forcing affected by the resolved LUCs in other domains. The statistical measures for the PXSMEC experiment in Table 10 show that using adjusted emissivity in version 3.7.3 leads to improved model performance. For overall performance, ratio is increased from 0.58 to 0.92 , while $\sigma_{\text {diff }}$ decreased from $2.7^{\circ}$ to $2.1^{\circ} \mathrm{C}$, and $R$ is increased. The performance for estimating DCI clearly gets improved: $\mathrm{MBE}$ is increased from $-4.8^{\circ}$ to $-0.8^{\circ} \mathrm{C}$, ratio increased from 0.47 to $0.87, \sigma_{\text {diff }}$ decreased from $4.4^{\circ}$ to $3.3^{\circ} \mathrm{C}$, and $R$ is also increased evidently. At the same time, both the maximum and minimum temperatures also display a good performance: MBE for the minimum temperature decreases from $2.7^{\circ}$ to $1.5^{\circ} \mathrm{C}$, resulting in a smaller warm bias, while that for the maximum temperature changes from a relatively large cold bias $\left(-2.1^{\circ} \mathrm{C}\right)$ to a relatively small warm bias $\left(0.4^{\circ} \mathrm{C}\right)$. The results show the importance of the surface emissivity in modeling near-surface air temperature and also imply some uncertainty in mesoscale modeling caused by surface parameters (e.g., Mölders 2001).

\section{Summary and conclusions}

In this study, we evaluate and compare the performances of Noah and Pleim-Xiu land surface models coupled with MM5. The study focuses on the evaluation and comparison of spatial and temporal variations of near-surface air temperature for four different experiment schemes using the GÖTE2001 data of 2-m air temperature. These four schemes are designed to reveal 1) the effect of Eta and MRF PBL schemes in the Noah LSM and 2) the effect of two approaches for soil moisture initialization in the Pleim-Xiu LSM. At the

TABle 6. As in Table 5, but for 14-20 May 2001 (cloudy or rainy days).

\begin{tabular}{|c|c|c|c|c|c|c|c|c|c|}
\hline \multirow[b]{2}{*}{ LUC } & \multirow[b]{2}{*}{ Flux $\left(\mathrm{W} \mathrm{m}^{-2}\right)$} & \multicolumn{2}{|c|}{ Noah-Eta } & \multicolumn{2}{|c|}{ Noah-MRF } & \multicolumn{2}{|c|}{ PX-SMEC } & \multicolumn{2}{|c|}{ PX-SMLU } \\
\hline & & Day & Night & Day & Night & Day & Night & Day & Night \\
\hline \multirow[t]{3}{*}{ Urban $(m=57)$} & SH & 148 & 36 & 145 & 26 & 118 & -22 & 118 & -21 \\
\hline & LH & 5 & 2 & 5 & 2 & 82 & 19 & 72 & 17 \\
\hline & $G$ & -33 & 37 & -34 & 44 & 1 & -32 & -3 & -18 \\
\hline \multirow[t]{3}{*}{ Crop $(m=69)$} & SH & 66 & -18 & 59 & -20 & 96 & -23 & 96 & -21 \\
\hline & LH & 80 & 8 & 91 & 5 & 86 & 13 & 71 & 13 \\
\hline & $G$ & -11 & 12 & -12 & 17 & 4 & -30 & 0 & -20 \\
\hline \multirow{3}{*}{ Forest $(m=810)$} & SH & 86 & -9 & 73 & -14 & 94 & -15 & 116 & -15 \\
\hline & LH & 92 & 10 & 97 & 8 & 102 & 16 & 79 & 12 \\
\hline & $G$ & -13 & 13 & -14 & 16 & 2 & -34 & -3 & -23 \\
\hline \multirow[t]{2}{*}{ Water $(m=819)$} & SH & 19 & 6 & 4 & -4 & 8 & 5 & 10 & 5 \\
\hline & LH & 93 & 65 & 100 & 64 & 45 & 31 & 46 & 34 \\
\hline
\end{tabular}




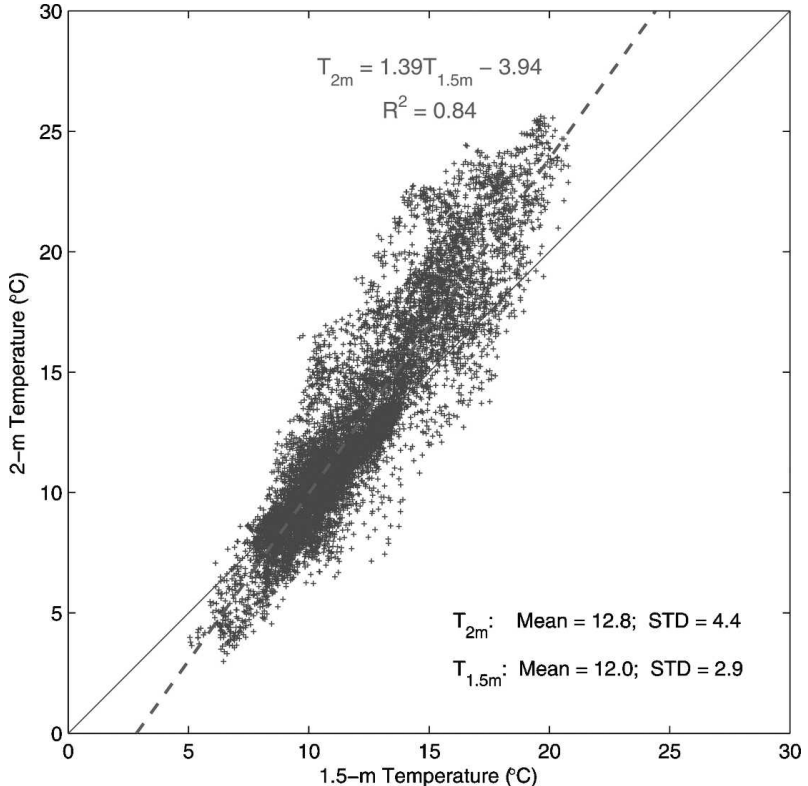

FIG. 10. Scatterplot of modeled 1.5- vs 2-m air temperature with PX-SMEC (version 3.7.2). The results are based on hourly air temperature during the period 7-20 May 2001 over the 29 observational sites. The statistical parameters (mean, STD) are presented within the plot (temporal sample number: $n=336$; spatial sample number: $m=29$ ). The least squares fitting line (dashed line) with explained variance $R^{2}$ is presented to show the relationship between $1.5-\mathrm{m}$ air temperature $T_{1.5 \mathrm{~m}}$ and $2-\mathrm{m}$ air temperature $T_{2 \mathrm{~m}}$.

same time, the differences between the Noah LSM and Pleim-Xiu LSM are also compared. These experiments are conducted in the context of MM5, version 3.7.2. The analyses suggest the following:

1) There is no systematic temperature bias for all the experiments (Noah-Eta, Noah-MRF, PX-SMEC, and PX-SMLU), but there is a daytime cold bias and a nighttime warm bias for Noah-Eta, NoahMRF, and PX-SMEC schemes, especially under clear-sky conditions. This results in the overestimate of the minimum temperature and the underestimate of the maximum temperature, which causes an overall underestimated DCI. This underestimate also depends on weather conditions. In contrast, the PXSMLU scheme performs relatively well in estimating the near-surface air temperature, especially during the daytime (e.g., maximum temperature). The DCI can therefore be simulated fairly well.

2) There is no evident difference in predicting nearsurface air temperature between Eta and MRF PBLs coupled with the Noah LSM (Noah-Eta and Noah-MRF), but Eta PBL performs slightly better than MRF PBL. However, there is an evident difference between the simulations using the PX-
TABLE 7. Comparison of statistical parameters of TS (cf. Fig. 3), DCI (cf. Fig. 4), Tmin, and Tmax (cf. Fig. 5) using different screen heights in Pleim-Xiu LSM for PX-SMEC experiments.

\begin{tabular}{|c|c|c|c|}
\hline Element & Statistics & $\begin{array}{c}\text { PX-SMEC } \\
\text { (control)* } \\
\text { screen height: } \\
1.5 \mathrm{~m}\end{array}$ & $\begin{array}{c}\text { PX-SMEC } \\
\text { (sensitivity) } \\
\text { screen height } \\
2 \mathrm{~m}\end{array}$ \\
\hline \multirow[t]{5}{*}{ TS } & MBE & -0.1 & 0.7 \\
\hline & RMSE & 2.7 & 2.2 \\
\hline & Ratio & 0.58 & 0.88 \\
\hline & $\sigma_{\text {diff }}$ & 2.7 & 2.1 \\
\hline & $R$ & 0.87 & 0.90 \\
\hline \multirow[t]{5}{*}{ DCI } & MBE & -4.8 & -1.4 \\
\hline & RMSE & 6.5 & 3.6 \\
\hline & Ratio & 0.47 & 0.81 \\
\hline & $\sigma_{\text {diff }}$ & 4.4 & 3.3 \\
\hline & $R$ & 0.71 & 0.83 \\
\hline \multirow[t]{5}{*}{ Tmin } & MBE & 2.7 & 1.6 \\
\hline & RMSE & 3.8 & 3.0 \\
\hline & Ratio & 0.39 & 0.56 \\
\hline & $\sigma_{\text {diff }}$ & 2.6 & 2.5 \\
\hline & $R$ & 0.37 & 0.48 \\
\hline \multirow[t]{5}{*}{ Tmax } & MBE & -2.1 & 0.2 \\
\hline & RMSE & 3.6 & 2.4 \\
\hline & Ratio & 0.61 & 0.98 \\
\hline & $\sigma_{\text {diff }}$ & 3.0 & 2.4 \\
\hline & $R$ & 0.70 & 0.83 \\
\hline
\end{tabular}

* The statistical parameters for PX-SMEC shown in Figs. 3-5 are listed in this table as those for PX-SMEC (control) for convenience of comparison.

SMEC and PX-SMLU schemes, in which different soil initialization is used in the Pleim-Xiu LSM. Using soil moisture at finescale for initialization in the LSM most likely contributed to the improvement of the model performance.

3) Noah-Eta and Noah-MRF schemes can simulate the urban effect reasonably well, whereas PXSMEC and PX-SMLU schemes do not show this capability very much. This is partly due to parameterization of vegetation properties for urban land

TABLE 8. Difference between two versions of MM5 in Noah LSM.

\begin{tabular}{lcc}
\hline \hline MM5 version & $\begin{array}{c}\text { Parameterization } \\
\text { for downward } \\
\text { longwave radiation* }\end{array}$ & $\begin{array}{c}\text { Parameterization } \\
\text { for upward } \\
\text { longwave radiation** }\end{array}$ \\
\hline Version 3.7.2 & GLW & $-\varepsilon \sigma T_{1}^{4}$ \\
Version 3.7.3 & $\varepsilon$ GLW & $-\varepsilon \sigma T_{24}^{4}$ \\
\hline
\end{tabular}

* GLW: longwave downward component of the flux at ground; $\varepsilon$ : emissivity at $9 \mu \mathrm{m}$ (longwave).

** Here $\sigma$ is Stefan-Boltzmann constant; $T_{1}$ is ground/canopy/ snowpack effective skin temperature, and $T_{24}$ is air temperature at the first model level above ground. 
TABLE 9. Difference between two versions of MM5 in LANDUSE.TBL.* Only LUCs with difference in emissivity and/ or roughness length are listed. The dash indicates unchanged.

\begin{tabular}{cccccc}
\hline \hline & \multicolumn{2}{c}{ Emissivity $(\%$ at $9 \mu \mathrm{m})$} & & \multicolumn{2}{c}{ Roughness length $(\mathrm{cm})$} \\
\cline { 2 - 3 } \cline { 5 - 6 } LUC** & Version & Version & & Version & Version \\
\cline { 6 - 7 } 3 & 3.7 .2 & 3.7 .3 & & 3.7 .2 & 3.7 .3 \\
5 & - & - & & 15 & 10 \\
7 & 0.99 & 0.98 & & - & - \\
8 & 0.985 & 0.96 & & - & - \\
9 & 0.88 & 0.93 & & 10 & 5 \\
15 & 0.90 & 0.95 & & 11 & 6 \\
19 & 0.94 & 0.97 & & - & - \\
23 & 0.85 & 0.90 & & 10 & 1 \\
\hline
\end{tabular}

* LANDUSE.TBL is an input table file for MM5 LSMs including parameter values for vegetation properties. Note that Noah and Pleim-Xiu LSMs use partial (not all) vegetation property parameters in this table file.

** Here 3 is irrigated cropland and pasture, 5 is cropland/grassland mosaic, 7 is grassland, 8 is shrubland, 9 is mixed shrubland/ grassland, 15 is mixed forest, 19 is barren or sparsely vegetated, and 23 is bare ground tundra [see also Xiu and Pleim (2001) for land use name]. Note that LUCs 7, 8, 15, 19, and 23 exist in the D1 and D2 domains used in this study and LUCs 3 and 9 do not exist in any domains. In this table, only LUC 5 exists in all domains (see also Table 2).

use category in the model. Comparison between Noah-Eta and Noah-MRF experiments shows that MRF PBL has a better performance in estimating UHI under clear sky conditions than Eta PBL, but
MRF PBL somewhat overestimates UHI intensity during the nighttime under the cloudy or rainy days. Also, all schemes show some difference between urban and rural areas in the diurnal mean bias error (MBE) of temperature.

4) The adjustment of screen height in the Pleim-Xiu LSM is necessary for model evaluation when compared with the observed air temperature measured at a different screen height.

In addition, the latest version of MM5 (version 3.7.3) is compared with the version 3.7.2 in simulating nearsurface air temperature using the Noah-Eta and PXSMEC schemes, respectively. The comparative results show that 1) for Noah LSM, version 3.7.3 has some improvement in overall model performance in nearsurface air temperature as compared with version 3.7.2, and 2) for the Pleim-Xiu LSM, version 3.7.3 has significant improvement in predicting near-surface air temperature relative to version 3.7.2.

Acknowledgments. The Faculty of Science at Göteborg University and Adlerbertska Stipendiefonden are thanked for their support to Junfeng Miao, and Dr. Klaus Wyser at the Swedish Meteorological and Hydrological Institute (SMHI) is greatly appreciated for his modeling support for this work. The authors also thank Dr. Fei Chen and Dr. Jimy Dudhia (NCAR) for their discussion on MM5-Noah LSM and Dr. Aijun Xiu

TABLE 10. Comparison between version 3.7.2 and version 3.7.3 for statistical parameters of TS, DCI, Tmin, and Tmax.

\begin{tabular}{|c|c|c|c|c|c|}
\hline \multirow[b]{2}{*}{ Element } & \multirow[b]{2}{*}{ Statistics } & \multicolumn{2}{|c|}{ Noah LSM experiment } & \multicolumn{2}{|c|}{ Pleim-Xiu LSM experiment } \\
\hline & & Noah-Eta_V3.7.2* & Noah-Eta_V3.7.3 & PX-SMEC_V3.7.2* & PX-SMEC_V3.7.3 \\
\hline \multirow[t]{5}{*}{ TS } & MBE & 0.0 & -0.4 & -0.1 & 0.6 \\
\hline & RMSE & 2.7 & 2.5 & 2.7 & 2.2 \\
\hline & Ratio & 0.62 & 0.68 & 0.58 & 0.92 \\
\hline & $\sigma_{\text {diff }}$ & 2.7 & 2.5 & 2.7 & 2.1 \\
\hline & $R$ & 0.86 & 0.88 & 0.87 & 0.90 \\
\hline \multirow[t]{5}{*}{ DCI } & MBE & -5.0 & -4.0 & -4.8 & -0.8 \\
\hline & RMSE & 6.3 & 5.4 & 6.5 & 3.4 \\
\hline & Ratio & 0.46 & 0.56 & 0.47 & 0.87 \\
\hline & $\sigma_{\text {diff }}$ & 3.9 & 3.6 & 4.4 & 3.3 \\
\hline & $R$ & 0.84 & 0.84 & 0.71 & 0.83 \\
\hline \multirow[t]{5}{*}{ Tmin } & MBE & 2.5 & 1.6 & 2.7 & 1.2 \\
\hline & RMSE & 3.6 & 2.9 & 3.8 & 2.7 \\
\hline & Ratio & 0.75 & 0.85 & 0.39 & 0.61 \\
\hline & $\sigma_{\text {diff }}$ & 2.6 & 2.4 & 2.6 & 2.4 \\
\hline & $R$ & 0.49 & 0.57 & 0.37 & 0.55 \\
\hline \multirow{5}{*}{ Tmax } & MBE & -2.5 & -2.4 & -2.1 & 0.4 \\
\hline & RMSE & 3.7 & 3.7 & 3.6 & 2.6 \\
\hline & Ratio & 0.67 & 0.68 & 0.61 & 1.02 \\
\hline & $\sigma_{\text {diff }}$ & 2.7 & 2.8 & 3.0 & 2.5 \\
\hline & $R$ & 0.77 & 0.74 & 0.70 & 0.82 \\
\hline
\end{tabular}

* The statistical parameters for Noah-Eta and PX-SMEC shown in Figs. 3-5 are listed in this table as those for Noah-Eta_V3.7.2 and PX-SMEC_V3.7.2, respectively, for convenience of comparison. The PX-SMEC_V3.7.2 experiment is also the same as PX-SMEC (control) experiment in Table 7. 
(University of North Carolina at Chapel Hill) for her discussion about MM5/Pleim-Xiu LSM with the first author. Special thanks are also given to Dr. Fei Chen for his valuable comments on the manuscript. The Swedish Research Council for Environment, Agricultural Sciences and Spatial Planning (FORMAS) and the Swedish Research Council (VR) are also thanked for their support to Deliang Chen. Also, the three anonymous reviewers are greatly appreciated for their valuable comments and constructive suggestions to improve the manuscript. This paper is Contribution Number 6 from TELLUS, the Center for Earth Systems Science at Göteborg University.

\section{REFERENCES}

Avissar, R., and R. A. Pielke, 1989: A parameterization of heterogeneous land surfaces for atmospheric numerical models and its impact on regional meteorology. Mon. Wea. Rev., 117, 2113-2136.

Borne, K., and Coauthors, 2005: Data report on measurements of meteorological- and air pollution variables during the campaign GÖTE-2001. Research Rep. C67, Earth Sciences Centre, Göteborg University, Gothenburg, Sweden, 28 pp.

Case, J. L., J. Manobianco, A. V. Dianic, M. W. Wheeler, D. E. Harms, and C. R. Parks, 2002: Verification of high-resolution RAMS forecasts over east-central Florida during the 1999 and 2000 summer months. Wea. Forecasting, 17, 1133-1151.

Chen, F., 2005: Variability in global land surface energy budgets during 1987-1988 simulated by an off-line land surface model. Climate Dyn., 24, 667-684.

_, and R. Avissar, 1994a: Impact of land-surface moisture variability on local shallow convective cumulus and precipitation in large-scale models. J. Appl. Meteor., 33, 1382-1401.

— erogeneity on mesoscale heat fluxes. J. Appl. Meteor., 33, $1323-1340$

- and J. Dudhia, 2001a: Coupling an advanced land surfacehydrology model with the Penn State-NCAR MM5 modeling system. Part I: Model implementation and sensitivity. Mon. Wea. Rev., 129, 569-585.

- , and — 2001b: Coupling an advanced land surfacehydrology model with the Penn State-NCAR MM5 modeling system. Part II: Preliminary model validation. Mon. Wea. Rev., 129, 587-604.

_ , and Coauthors, 1996: Modeling of land-surface evaporation by four schemes and comparison with FIFE observations. $J$. Geophys. Res., 101 (D3), 7251-7268.

_- T. T. Warner, and K. Manning, 2001: Sensitivity of orographic moist convection to landscape variability: A study of the Buffalo Creek, Colorado, flash flood case of 1996. J. Atmos. Sci., 58, 3204-3223.

- , Y. Liu, H. Kusaka, M. Tewari, J.-W. Bao, C.-F. Lo, and K.-H. Lau, 2004: Challenge of forecasting urban weather with NWP models. Preprints, Fifth WRF/14th MM5 Users' Workshop, Boulder, CO, NCAR, 34-42.

Dandou, A., M. Tombrou, E. Akylas, N. Soulakellis, and E. Bossioli, 2005: Development and evaluation of an urban parameterization scheme in the Penn State/NCAR Mesoscale Model (MM5). J. Geophys. Res., 110, D10102, doi:10.1029/ 2004JD005192.
Desborough, C. E., 1999: Surface energy balance complexity in GCM land surface models. Climate Dyn., 15, 389-403.

Dudhia, J., 1989: Numerical study of convection observed during the Winter Monsoon Experiment using a mesoscale twodimensional model. J. Atmos. Sci., 46, 3077-3107.

- 1993: A nonhydrostatic version of the Penn State-NCAR mesoscale model: Validation tests and simulation of an Atlantic cyclone and cold front. Mon. Wea. Rev., 121, 14931513.

Dupont, S., T. L. Otte, and J. K. S. Ching, 2004: Simulation of meteorological fields within and above urban and rural canopies with a mesoscale model. Bound.-Layer Meteor., 113, 111-158.

Ek, M. B., K. E. Mitchell, Y. Lin, E. Rogers, P. Grunmann, V. Koren, G. Gayno, and J. D. Tarpley, 2003: Implementation of Noah land surface model advances in the National Centers for Environmental Prediction operational Mesoscale Eta Model. J. Geophys. Res., 108, 8851, doi:10.1029/ 2002JD003296.

Fan, H.-L., and D. J. Sailor, 2005: Modeling the impacts of anthropogenic heating on the urban climate of Philadelphia: A comparison of implementations in two PBL schemes. Atmos. Environ., 39, 73-84.

Grell, G. A., J. Dudhia, and D. R. Stauffer, 1995: A description of the fifth-generation Penn State/NCAR Mesoscale Model (MM5). NCAR Tech. Note NCAR/TN-398+STR, 122 pp.

—, S. Emeis, W. R. Stockwell, T. Schoenemeyer, R. Forkel, J. Michalakes, R. Knoche, and W. Seidl, 2000: Application of a multiscale, coupled MM5/chemistry model to the complex terrain of the VOTALP valley campaign. Atmos. Environ. 34, 1435-1453.

Grossman-Clarke, S., J. A. Zehnder, W. L. Stefanov, Y. Liu, and M. A. Zoldak, 2005: Urban modifications in a mesoscale meteorological model and the effects on near-surface variables in an arid metropolitan region. J. Appl. Meteor., 44, 12811297.

Henderson-Sellers, A., A. J. Pitman, P. K. Love, P. Irannejad, and T. H. Chen, 1995: The Project for Intercomparison of Land Surface Parameterization Schemes (PILPS): Phases 2 and 3. Bull. Amer. Meteor. Soc., 76, 489-503.

_, K. McGuffie, and A. J. Pitman, 1996: The Project for Intercomparison of Land-surface Parametrization Schemes (PILPS): 1992 to 1995. Climate Dyn., 12, 849-859.

Hogrefe, C., and Coauthors, 2001: Evaluating the performance of regional-scale photochemical modelling systems: Part Imeteorological predictions. Atmos. Environ., 35, 4159-4174.

Hogue, T. S., L. Bastidas, H. Gupta, S. Sorooshian, K. Mitchell, and W. Emmerich, 2005: Evaluation and transferability of the Noah land surface model in semiarid environments. $J$. Hydrometeor., 6, 68-84.

Hong, S.-Y., and H.-L. Pan, 1996: Nonlocal boundary layer vertical diffusion in a medium-range forecast model. Mon. Wea. Rev., 124, 2322-2339.

Jacquemin, B., and J. Noilhan, 1990: Sensitivity study and validation of a land surface parameterization using the HAPEXMOBILHY data set. Bound.-Layer Meteor., 52, 93-134.

Janjić, Z. I., 1990: The step-mountain coordinate: Physical package. Mon. Wea. Rev., 118, 1429-1443. , 1994: The step-mountain Eta coordinate model: Further developments of the convection, viscous sublayer, and turbulence closure schemes. Mon. Wea. Rev., 122, 927-945.

Kain, J. S., 2004: The Kain-Fritsch convective parameterization: An update. J. Appl. Meteor., 43, 170-181. 
Kemball-Cook, S., Y. Jia, C. Emery, R. Morris, Z. Wang, and G. Tonnesen, cited 2004: 2002 annual MM5 36 km simulation to support WRAP CMAQ visibility modeling for the Section 308 SIP/TIP: Preliminary report on the initial 200236 $\mathrm{km}$ MM5 simulation performed during 2003. [Available online at http://pah.cert.ucr.edu/aqm/308/reports/mm5/ 2002_MM5_2003WRAPr.pdf.]

Koren, V., J. Schaake, K. Mitchell, Q.-Y. Duan, F. Chen, and J. M. Baker, 1999: A parameterization of snowpack and frozen ground intended for NCEP weather and climate models. $J$. Geophys. Res., 104 (D16), 19 569-19585.

Landberg, L., L. Myllerup, O. Rathmann, E. L. Petersen, B. H. Jørgensen, J. Badger, and N. G. Mortensen, 2003: Wind resource estimation-An overview. Wind Energy, 6, 261-271.

Liu, Y., F. Chen, T. Warner, and J. Basara, 2006: Verification of a mesoscale data- assimilation and forecasting system for the Oklahoma city area during the Joint Urban 2003 Field Project. J. Appl. Meteor. Climatol., 45, 912-929.

Mahrt, L., and M. Ek, 1984: The influence of atmospheric stability on potential evaporation. J. Climate Appl. Meteor., 23, 222234.

_- and H.-L. Pan, 1984: A two-layer model of soil hydrology. Bound.-Layer Meteor., 29, 1-20.

Miao, J.-F., 2006: Meteorological modelling in coastal areasLocal climate and air quality. Ph.D. thesis A107, Earth Sciences Centre, Göteborg University, Göteborg, Sweden, 190 pp.

- D. Chen, and K. Wyser, 2006: Modelling subgrid scale dry deposition velocity of $\mathrm{O}_{3}$ over the Swedish west coast with MM5-PX model. Atmos. Environ., 40, 415-429.

—, and Coauthors, 2007: Evaluation of MM5 mesoscale model at local scale for air quality applications over the Swedish west coast: Influence of PBL and LSM parameterizations. Meteor. Atmos. Phys., in press.

Mlawer, E. J., S. J. Taubman, P. D. Brown, M. J. Iacono, and S. A. Clough, 1997: Radiative transfer for inhomogeneous atmospheres: RRTM, a validated correlated-K model for the longwave. J. Geophys. Res., 102 (D14), 16 663-16 682.

Mölders, N., 2001: On the uncertainty in mesoscale modeling caused by surface parameters. Meteor. Atmos. Phys., 76, 119 141.

- and M. A. Olson, 2004: Impact of urban effects on precipitation in high latitudes. J. Hydrometeor., 5, 409-429.

— , and J. E. Walsh, 2004: Atmospheric response to soil-frost and snow in Alaska in March. Theor. Appl. Climatol., 77, $77-105$.

Noilhan, J., and S. Planton, 1989: A simple parameterization of land surface processes for meteorological models. Mon. Wea. Rev., 117, 536-549.

Olerud, D., and A. Sims, cited 2003: MM5 sensitivity modeling in support of VISTAS (Visibility Improvement-State and Tribal Association): Task 2e deliverable. [Available online at http://www.baronams.com/projects/VISTAS/reports/ VISTAS_TASK2e_draft.pdf.]

Otte, T. L., A. Lacser, S. Dupont, and J. K. S. Ching, 2004: Implementation of an urban canopy parameterization in a mesoscale meteorological model. J. Appl. Meteor., 43, 1648-1665.
Pan, H.-L., and L. Mahrt, 1987: Interaction between soil hydrology and boundary-layer development. Bound.-Layer Meteor., 38, $185-202$.

Pitman, A. J., and Coauthors, 1999: Key results and implications from phase 1(c) of the Project for Intercomparison of Landsurface Parametrization Schemes. Climate Dyn., 15, 673-684.

Pleim, J. E., and J. S. Chang, 1992: A non-local closure model for vertical mixing in the convective boundary layer. Atmos. Environ., 26A, 965-981.

- and A. Xiu, 1995: Development and testing of a surface flux and planetary boundary layer model for application in mesoscale models. J. Appl. Meteor., 34, 16-32.

_ , and _ 2003: Development of a land surface model. Part II: Data assimilation. J. Appl. Meteor., 42, 1811-1822.

Polcher, J., and Coauthors, 1998: A proposal for a general interface between land surface schemes and general circulation models. Global Planet. Change, 19, 261-276.

Sandwell, D. T., 1987: Biharmonic spline interpolation of GEOS-3 and SEASAT altimeter data. Geophys. Res. Lett., 14, 139142

Seaman, N. L., 2000: Meteorological modelling for air-quality assessments. Atmos. Environ., 34, 2231-2259.

Sridhar, V., R. L. Elliott, F. Chen, and J. A. Brotzge, 2002: Validation of the Noah-OSU land surface model using surface flux measurements in Oklahoma. J. Geophys. Res., 107, 4418, doi:10.1029/2001JD001306.

,$- \ldots$, and — 2003: Scaling effects on modelled surface energy-balance components using the Noah-OSU land surface model. J. Hydrol., 280, 105-123.

Tilley, J. S., and A. H. Lynch, 1998: On the applicability of current land surface schemes for Arctic tundra: An intercomparison study. J. Geophys. Res., 103 (D22), 29 051-29 063.

Tonnesen, G., and Coauthors, cited 2005: 2004 interim report for the Western Regional Air Partnership (WRAP) Regional Modeling Center (RMC). WGA Contract 30203. [Available online at http://pah.cert.ucr.edu/aqm/308/reports/final/ 2004_RMC_interim_report_final.pdf.]

Trier, S. B., F. Chen, and K. W. Manning, 2004: A study of convection initiation in a mesoscale model using high-resolution land surface initial conditions. Mon. Wea. Rev., 132, 2954 2976.

Xiu, A., and J. E. Pleim, 2001: Development of a land surface model. Part I: Application in a mesoscale meteorological model. J. Appl. Meteor., 40, 192-209.

Zehnder, J. A., 2002: Simple modifications to improve fifthgeneration Pennsylvania State University-National Center for Atmospheric Research Mesoscale Model performance for the Phoenix, Arizona, metropolitan area. J. Appl. Meteor., 41, 971-979.

Zhong, S.-Y., and J. Fast, 2003: An evaluation of the MM5, RAMS, and Meso-Eta models at subkilometer resolution using VTMX field campaign data in the Salt Lake valley. Mon. Wea. Rev., 131, 1301-1322.

_, H.-J. In, X.-D. Bian, J. Charney, W. Heilman, and B. Potter, 2005: Evaluation of real-time high-resolution MM5 predictions over the Great Lakes region. Wea. Forecasting, 20, $63-$ 81. 
Copyright of Journal of Applied Meteorology \& Climatology is the property of American Meteorological Society and its content may not be copied or emailed to multiple sites or posted to a listserv without the copyright holder's express written permission. However, users may print. download, or email articles for individual use. 